\title{
Activity of iron pyrite towards low-temperature ammonia production
}

\author{
Israel Temprano, Tao Liu and Stephen J. Jenkins* \\ Department of Chemistry, University of Cambridge, Lensfield Road, Cambridge, CB2 1EW \\ Corresponding Author: S.J. Jenkins, tel: +44 1223 336502, e-mail: sjj24@ cam.ac.uk
}

\begin{abstract}
In this work we report the characteristics of iron pyrite toward the production of ammonia at low temperatures under ultra-high vacuum conditions. We review (with additional unpublished details) our previous systematic study of nitrogen and hydrogen adsorption on single-crystal iron pyrite $\left(\mathrm{FeS}_{2}\right)$ and summarise our earlier findings regarding the possibility of ammonia synthesis on this material. We also present new results concerning the adsorption of nitrogen and hydrogen on two related materials, namely molybdenum-treated iron pyrite surfaces and iron pyrite nanostructures deposited on a gold single-crystal. On the bare iron pyrite samples, ammonia is produced upon hydrogenation of preadsorbed $\mathrm{N}$ species at $230 \mathrm{~K}$, demonstrating that all hydrogenation steps are possible at low pressures and temperatures. Nitrogen adsorbs molecularly on $\mathrm{FeS}_{2}\{100\}$ at low temperatures, desorbing at $130 \mathrm{~K}$, but does not adsorb dissociatively even at pressures up to 1 bar. Adsorbed nitrogen species can, however, be obtained through exposure to excited nitrogen species. Hydrogen adsorbs on $\mathrm{FeS}_{2}\{100\}$, but only in the presence of an incandescent Ta filament. Recombinative desorption of $\mathrm{H}_{2}$ occurs at $225 \mathrm{~K}$ and is accompanied by desorption of $\mathrm{H}_{2} \mathrm{~S}$ at $260 \mathrm{~K}$. On the molybdenum-treated iron-pyrite, no appreciable $\mathrm{N}_{\text {ads }}$ species were detected under the experimental conditions studied, and the same is true for iron pyrite nanostructures on $\mathrm{Au}\{111\}$. We also provide further details of our efficient and reproducible method for preparing wellordered stoichiometrically pure $\mathrm{FeS}_{2}\{100\}$ suitable for surface science studies.
\end{abstract}

\section{Introduction}

It is estimated that, through the production of large amounts of fertilizers, industrial nitrogen fixation 
currently sustains the production of food for more than half the human population [1]. The precarious situation of global food supply is likely to be exacerbated by an ever growing global population and the limited uncultivated farmable land remaining (estimated to be $20 \%$ of the total) [1-4]. This makes the effective production of ammonia from atmospheric nitrogen arguably the single chemical process for which sizeable progress is most urgently needed $[\underline{5}, \underline{6}]$.

Over 150 million metric tons of ammonia are industrially produced every year through the catalytic Haber-Bosch process [2, 7]. Despite great efforts in improving this crucial industrial process, the high temperatures and pressures required make it hugely energy-intensive [2]. In a sharp contrast, the enzymatic synthesis of ammonia is carried under ambient temperature and pressure [ㅇ-10]. Intriguingly, while the industrial Haber-Bosch process primarily uses iron based catalysts, with sulphur being one of the main factors that reduce catalytic activity, efforts in protein crystallography have revealed that the enzymatic active sites (in nitrogenases) are composed of iron sulphide clusters [11]. These nitrogenase catalytic centres are commonly referred to as the Mo-Cofactor, as they present an apex transition metal atom (typically Mo) coordinated to the rest of the cluster, which is believed to influence the adsorption and stability of $\mathrm{N}_{2}[\underline{12}, \underline{13]}$.

Multiple factors contribute to the difficulty of producing ammonia from atmospheric $\mathrm{N}_{2}$ [14]. First, dissociation of the very strong triple bond of $\mathrm{N}_{2}$ is recognized as the rate determining step (RDS) in the industrial process. Molecular nitrogen is relatively inert owing to the strength of its triple bond, nonpolarity and high ionization potential [15]. Iron is a good catalyst for the dissociative adsorption of $\mathrm{N}_{2}$, but even so this apparently rate-determining step proceeds at appreciable rates only at elevated temperatures [14]. High temperature is also beneficial in speeding up other steps that may prove ratelimiting, including hydrogenation of surface intermediates and eventual desorption of the product [16, 17]. The stoichiometry of the ammonia synthesis reaction, however, implies that high pressures are also then needed to ensure tolerable yield (high temperature favours the reactants as the process is 
exothermic). As a result the Haber-Bosch process for catalytic synthesis of ammonia is estimated to account for over $1 \%$ of the world's annual energy production [2-4].

Several studies suggest that ammonia formation in nitrogenases occurs via a non-dissociative mechanism, involving the activation and hydrogenation of molecular $\mathrm{N}_{2(\mathrm{ads})}$ species on the surface of the $\mathrm{FeS}_{\mathrm{x}}$ cluster $[\underline{8}, \underline{11}, \underline{18}]$. Moreover, iron sulphide (pyrite) is believed to have played an essential role in the global biogeochemical sulphur cycle, as the reactivity of iron sulphide clusters in nitrogenases and hydrogenases suggest [19]. In consequence iron sulphide is a material of great importance in many environmentally and biologically important reactions [20-23]. Pyrite therefore emerges as an intriguing candidate to study the chemistry of $\mathrm{FeS}_{\mathrm{x}}$ centres in biological systems, and towards a possible biomimetic approach for the lowtemperature heterogeneous catalytic formation of ammonia. Hence we resolved to study the chemical activity of pyrite towards the species involved in the synthesis of ammonia, and to explore several bioinspired approaches in an attempt to understand the crucial factors that make this material the choice for the natural fixation of atmospheric $\mathrm{N}_{2}$.

In this article we report a systematic study of the activity of naturally grown pyrite towards the hydrogenation of adsorbed nitrogen species. We review the adsorption of $\mathrm{N}_{2}$, and $\mathrm{H}_{2}$ using as-grown $\mathrm{FeS}_{2}\{100\}$ as model material, as well as the formation of ammonia under ultra-high vacuum (UHV) conditions, some of which has been published in detail elsewhere $[\underline{24}, \underline{25}]$. These fundamental steps are the key to evaluate the kinetics of the formation of ammonia, and have been thoroughly studied and debated in the context of the Haber-Bosch process. Initially, ground-breaking work by Gerhard Ertl during the 1970s and 1980s [1]; [2]; [3]; [4] suggested that the rate-determining step in the Haber-Bosch process is likely to be the adsorption of nitrogen. However, the dynamics of $\mathrm{N}_{2}$ dissociative adsorption on Fe surfaces have been revealed to be surprisingly complex, since the low sticking probability of $\mathrm{N}_{2}$ does not appear to be due to a significant activation barrier to the actual dissociation process, instead arising from a barrier to entry into an unusual molecular precursor state [5]. To further complicate the issue, Strongin and Somorjai [6] have shown that the desorption of ammonia may be effectively rate-limiting 
under industrial conditions, due to $\mathrm{NH}_{3}$ blocking of sites for $\mathrm{N}_{2}$ adsorption. Furthermore we present our efforts to study the influence of the chemical composition (through Mo-doping), and size (through the formation of $\mathrm{Fe}_{\mathrm{x}} \mathrm{S}_{\mathrm{y}}$ nanoclusters) towards the adsorption of $\mathrm{N}_{2}$ on iron sulphide. We also discuss a convenient, efficient and reproducible method for preparing well-ordered naturally-occurring $\mathrm{FeS}_{2}\{100\}$, since pyrite surfaces are highly prone to crystallographic disordering, which has a great impact on the reproducibility of studies of their surface reactivity [19, 21, 26-28].

\section{Experimental Details}

The experimental work was performed in an ultra-high vacuum (UHV) stainless steel chamber (base pressure $<2 \times 10^{-10}$ mbar), equipped with a 3-grid LEED optics (VG RFA 640), an electron gun (VSW EG10), a concentric hemispherical analyser (VSW HA50), an ion gun (VSW AS10), and a quadrupole mass spectrometer (Hiden HAL201) installed on a retractable linear drive.

Naturally-occurring pyrite single crystals with well-developed $\{100\}$ habit planes were purchased from Manchester Minerals as $2 \times 2 \times 2 \mathrm{~cm}^{3}$ cubes. The crystals were mechanically machined into $10 \times 8 \times 1$ $\mathrm{mm}^{3}$ thin films with one surface left as naturally-grown. The back of the crystal was glued by an $\mathrm{Ag}$ silicate paste (Agar Scientific) onto a Ta foil (thickness: $0.05 \mathrm{~mm}$ ), along the edges of which $0.5 \mathrm{~mm} \mathrm{Ta}$ wires were spot-welded. These served as structural supports (running parallel along two opposite sides of the crystal film) and intimately sandwich the crystal, and as heating wires. This assembly was then spotwelded to the sample holder. An alumel-chromel thermocouple junction was glued at the back of the crystal using Ag silicate paste for sample temperature measurements. Calibration of our temperature recording system implied a systematic error of less than $10 \mathrm{~K}$, primarily due to degradation of the silicate paste over time, and was corrected accordingly. The sample manipulator can be filled with liquid nitrogen to cool the crystal down to a temperature of $165 \mathrm{~K}$.

As discussed in the next section, an ex situ acid pre-treatment was found to be advantageous in greatly reducing the number of sputter/anneal cycles needed to clean the surface in vacuo. A typical procedure is 
as follows: $30 \mathrm{~min}$ ultrasonication in isopropanol followed by $30 \mathrm{~min}$ in deionized water, and then in 200 $\mathrm{ml} 1 \mathrm{M} \mathrm{HCl}$ solution for 10 minutes; finally, rinsing and ultrasonication in deionized water. Subsequently the in vacuo cleaning procedure consisted in cycles of $200 \mathrm{eV} \mathrm{He}^{+}$sputtering (He BIP plus, Air Products) followed by $600 \mathrm{~K}$ annealing. Since the VSW AS10 ion gun produces an ion beam with a fixed nominal kinetic energy of $500 \mathrm{eV}$ for singly-charged ions with the sample at earth, we applied a positive bias potential to the sample to retard the kinetic energy of positively charged ions. Typically, a single sputtering cycle of less than 30 min was sufficient to reduce all contaminants below the detectable level using Auger spectroscopy. Additional annealing at $600 \mathrm{~K}$ for at least an hour was necessary to obtain a sharp (1x1) LEED pattern corresponding to the $\mathrm{FeS}_{2}\{100\}$ surface. Annealing beyond $600 \mathrm{~K}$ was avoided to prevent thermal decomposition.

Molybdenum deposition on $\mathrm{FeS}_{2}\{100\}$ was effected by exposing Mo at $170 \mathrm{~K}$ using an electron-beamassisted evaporator (Omicron EFM3) from a rod material (Goodfellow, $1.0 \mathrm{~mm}, 99.99 \%)$ at $910 \mathrm{eV}$ and $40 \mathrm{~mA}$ (emission). Mo coverage was controlled by varying the evaporation time, typically 0-25 minutes, while maintaining a constant evaporation flux $(\sim 25 \mu \mathrm{A})$. Mo coverage up to $1 \mathrm{ML}$ was estimated by the disappearance of the Auger Fe peak at $50 \mathrm{eV}$ and the absence of the (1x1) LEED pattern corresponding to $\mathrm{FeS}_{2}\{100\}$. Deposition rate was estimated at $0.2 \mathrm{ML} / \mathrm{min}$.

Iron sulphide clusters were produced on a clean $\mathrm{Au}\{111\}$ surface by electron-beam deposition of $\mathrm{Fe}$ (Goodfellow, $1.0 \mathrm{~mm}, 99.99 \%)$ under an atmosphere of $\mathrm{H}_{2} \mathrm{~S}\left(1 \times 10^{-6} \mathrm{mbar}\right)$ at $400 \mathrm{~K}$, followed by anneal to $673 \mathrm{~K}$ (under same pressure of $\mathrm{H}_{2} \mathrm{~S}$ ) for 15 minutes. Fe exposure was controlled by varying the evaporation time, typically $0-20$ minutes, while maintaining a constant evaporation flux $(\sim 15 \mu \mathrm{A})$. The amount of Fe and S present on the $\mathrm{Au}\{111\}$ after e-beam deposition was evaluated by AES.

\section{3. $\mathrm{FeS}_{2}$ single crystal preparation for UHV studies}

The preparation of reproducibly well-defined pyrite surfaces has been a challenging issue for detailed surface science studies of this material [26-28]. There are two common methods reported for the 
preparation of clean pyrite surfaces for studies under UHV conditions: (i) The in vacuo cleaving of a pyrite single crystal, and (ii) sputtering a naturally grown single crystal. Both methods have severe limitations; the former produces an essentially clean but macroscopically rough surface, with uncontrollable incidence of defects [29-31], while the latter induces severe surface disorder that cannot be readily removed by annealing, requiring special precautions to mitigate cumulative damage [르, $\underline{33}$. Low-mass sputtering gases with low kinetic energies are therefore normally preferred to clean pyrite surfaces in vacuo, such as the use of $200 \mathrm{eV} \mathrm{He}^{+}$instead of $500 \mathrm{eV}$ (or more) $\mathrm{Ar}^{+}$commonly used for metal surfaces, in order to minimize disordering [32]. The lower kinetic energy used with $\mathrm{He}^{+}$, however, compromises the sputtering efficiency. Multiple sputtering/annealing cycles are therefore required, and although the damage introduced in a single sputtering cycle is reduced, the overall cumulative damage is not.

\subsection{In vacuo cleaning of as-received $\mathrm{FeS}_{2}\{100\}$}

Auger electron spectroscopy (AES) data of as-received pyrite crystals, shown in Figure 1a, reveal that potassium $(250 \mathrm{eV})$, carbon $(273 \mathrm{eV})$ and oxygen $(510 \mathrm{eV})$ are the major contaminants on the surface. Sulphur $(153 \mathrm{eV})$ is predictably the most intense peak, whereas the intensities of Fe Auger peaks are greatly attenuated by the contaminants (a single peak at $50 \mathrm{eV}$ and three peaks above $600 \mathrm{eV}$ ). Both Fe and S AES peaks grow in intensity with gradual removal of surface contaminants by sputtering, as can be seen in Fig. 1b, corresponding to a total of $600 \mathrm{~min} 200 \mathrm{eV} \mathrm{He}^{+}$sputtering. 

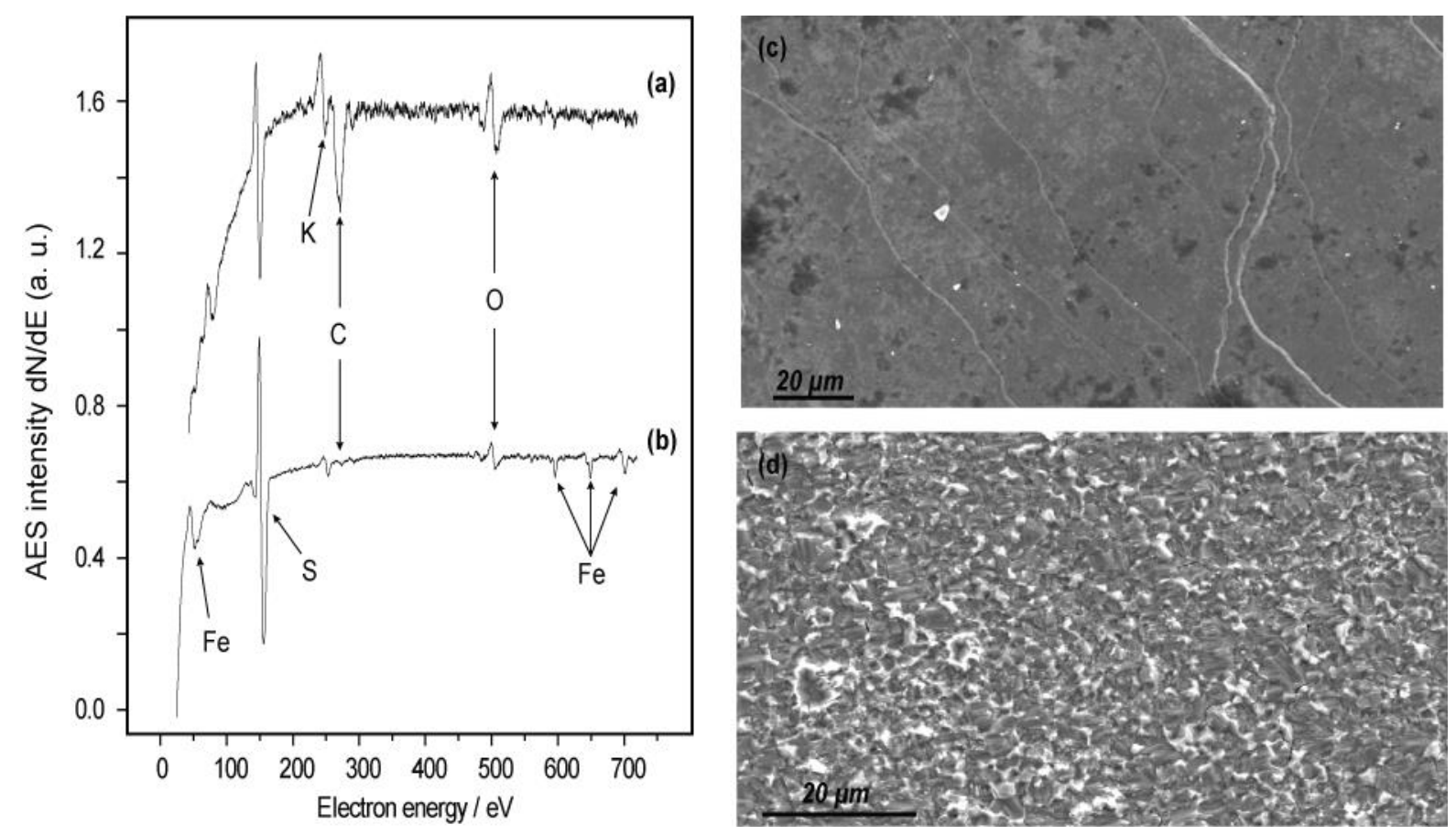

Figure 1. Auger spectra and corresponding SEM images of as-received $\mathrm{FeS}_{2}\{100\}$, prior to (a) and (c), and after total cumulative sputtering time of $600 \mathrm{~min}(\mathrm{~b})$ and (d).

The removal rate of the different contaminants was investigated by repeated cycles of $200 \mathrm{eV} \mathrm{He}^{+}$ sputtering and $10 \mathrm{~min}$ annealing at $600 \mathrm{~K}$. Auger spectra were recorded at the end of each cycle to monitor the contaminant levels. Auger peak-to-peak height ratios of individual contaminants versus sulphur $(153 \mathrm{eV})$ were used to monitor the cleaning process, as a function of total sputtering time (Fig. 2a). AES data indicates that the amount of carbon reduces to its minimum level after a relatively short cumulated 50 min sputtering. Potassium and oxygen are however more persistent on the surface, requiring in excess of 300 min sputtering to reach significantly reduced levels. As it can be seen in Fig. 1a, K and O are still detectable by AES even after a cumulative sputtering time of $600 \mathrm{~min}$, whilst Fe peaks at $50 \mathrm{eV}$ and above $600 \mathrm{eV}$ increase notably in intensity.

In the course of the initial $100 \mathrm{~min}$ of sputtering the S/Fe peak-peak ratio (Fig. 2c) decreases sharply, however after 300 minutes, the $\mathrm{S} / \mathrm{Fe}$ ratio eventually reaches a steady state minimum value. The sharp initial decay is associated with a combination of two factors: (i) the relatively fast rate of removal of the contaminants within the first 100 minutes of sputtering (Fig. 2a), leading to a rapid initial increase in the 
intensity of the $\mathrm{Fe}_{(50 \mathrm{eV})}$ peak; and (ii) the reduced slope of the secondary electron peak observed after several cleaning cycles (Fig. 1a). After a cumulated 100 minutes sputtering, the removal rate of $\mathrm{K}$ and $\mathrm{O}$ contaminants decreases, coinciding with a slower reduction in the $\mathrm{S} / \mathrm{Fe}$ ratio.

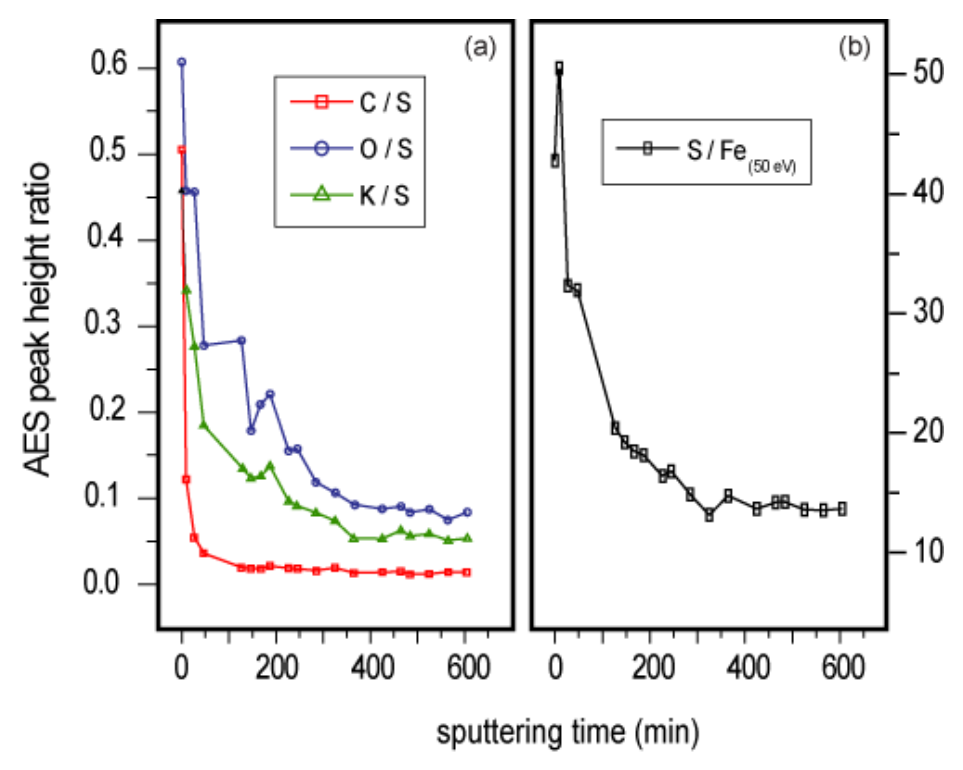

Figure 2. (a) Contaminant $\left(\mathrm{C}_{275 \mathrm{ev}}, \mathrm{O}_{510 \mathrm{ev}}\right.$ and $\left.\mathrm{K}_{252 \mathrm{ev}}\right)$ and (b) iron $\left(\mathrm{Fe}_{50 \mathrm{ev}}\right)$ AES peak-peak heights ratio to $\mathrm{S}_{153 \mathrm{ev}}$, as a function of sputtering time. A $10 \mathrm{~min}$ annealing treatment at $600 \mathrm{~K}$ was applied prior to recording each Auger spectrum.

In the course of in vacuo $\mathrm{He}^{+}$bombardment, optically visible rough black patches appear rapidly on the surface, which loses its metallic lustrous appearance. Scanning electron microscopy (SEM) images of asreceived pyrite surface show relatively smooth morphology (Fig. 1c), corresponding to the Auger spectrum in Fig. 1a. However after a total of $600 \mathrm{~min} 200 \mathrm{eV} \mathrm{He} \mathrm{H}^{+}$sputtering, corresponding to the AES spectrum in Fig. 1b, SEM images shown in Fig. 1d illustrate the extent of the cumulative damage caused to pyrite crystal structure by sputtering.

A (1x1) LEED pattern, albeit with high diffuse background, can be observed for the as received $\mathrm{FeS}_{2}\{100\}$ surface. This pattern disappears in the course of repeated the in vacuo cleaning process, until no diffracted electron beams can be distinguished, even after prolonged annealing of up to 48 hours at 600 $\mathrm{K}$ (not shown). These observations reveal the extent to which pyrite surfaces are prone to sputtering 
damage, with crystallographic disordering eventually became irreversible, in agreement with previous reports $[\underline{30}, \underline{31}]$.

\subsection{Effects of ex situ acid treatment}

In order to decrease the number of sputtering cycles needed to produce a contaminant-clear sample, ex situ acid treatment of as received, naturally grown $\mathrm{FeS}_{2}\{100\}$ was applied prior to introduction of the sample in the UHV chamber. This ex situ treatment consists of 30 minute sonication treatments in isopropanol and deionized water, followed by 10 minute sonication in a $1 \mathrm{M} \mathrm{HCl}$ solution, and a final rinse and sonication in deionized water.

Fig. 3a shows a typical Auger spectrum of an acid-treated surface prior to in vacuo sputtering/annealing. This spectrum compares very favourably with the spectrum in Fig. 1a, showing the high efficiency of the acid treatment in removing nearly all potassium and oxygen, even though oxygen-containing species, such as oxide, sulphate and hydrate species, are intrinsic to the pyrite surface exposed in air. The acid treatment shows high efficiency in dissolving these O-containing species, as well as any soluble potassium-containing contaminants. Furthermore, it can be seen that Fe AES peaks are clearly visible after acid treatment, before in vacuo cleaning, in marked contrast to the spectrum in Fig. 1a. 


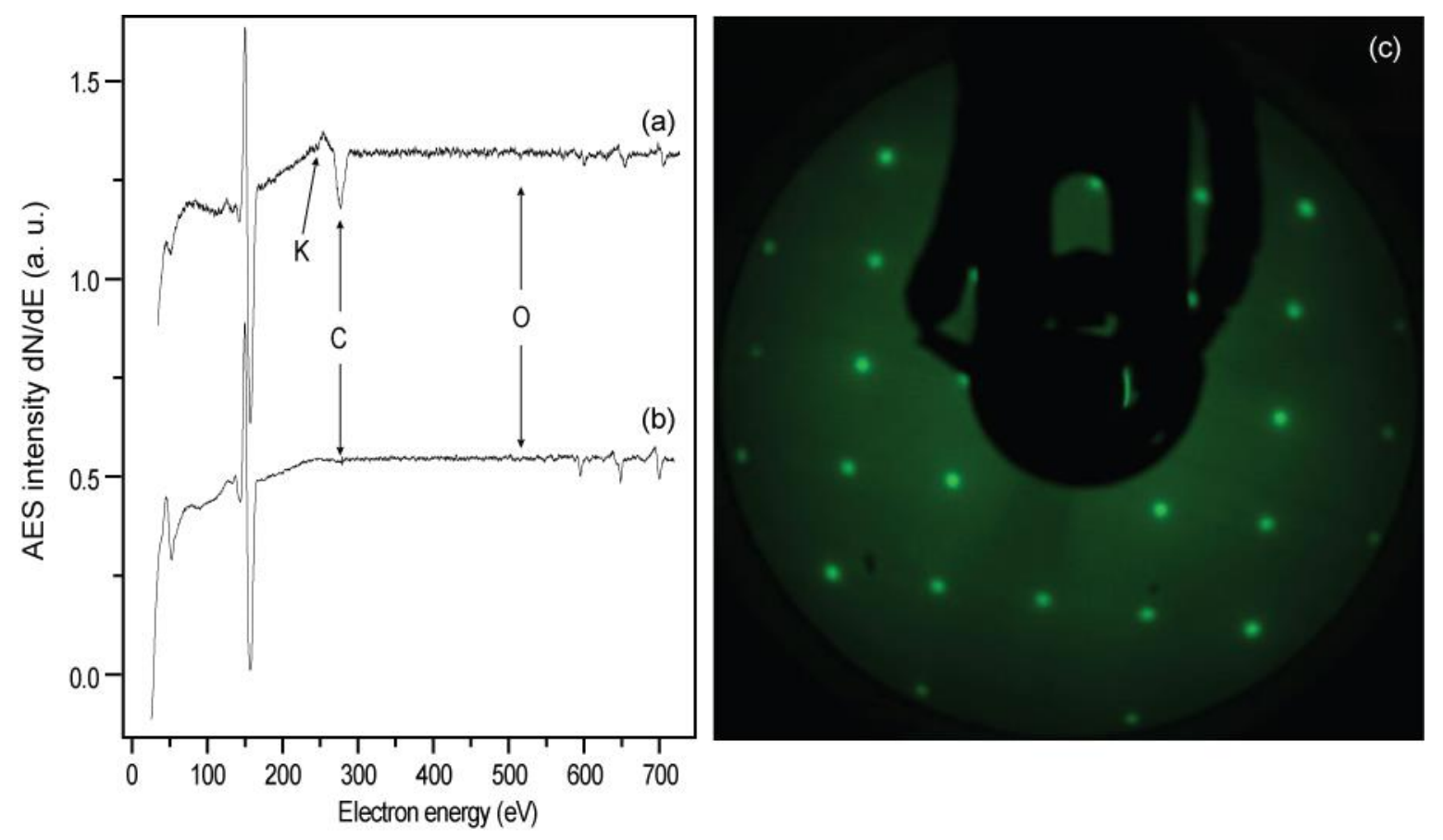

Figure 3. Auger spectra of as received $\mathrm{FeS}_{2}\{100\}$ after acid treatment, prior to (a) and after total sputtering time of $30 \mathrm{~min}(\mathrm{~b})$; (c) LEED pattern at $110 \mathrm{eV}$ of $\mathrm{FeS}_{2}\{100\}$ corresponding to spectrum (b) after 1-hour annealing at $600 \mathrm{~K}$.

The Auger spectrum in Fig. $3 b$ shows that all surface contaminants are already near the AES detection limit, after a single $\mathrm{He}^{+}$sputtering cycle of less than 30 minutes. The Auger peak ratios of carbon, oxygen and potassium with sulphur are $0.19,0.032$, and 0.019 respectively. These levels compare very favourably with the levels attained by much longer sputtering times in the absence of a prior acid treatment (as comparatively shown in Fig. 4). These results clearly reveal the efficiency of the above described acid treatment in substantially reducing the number of sputtering/annealing cycles needed for removal of surface contaminants. It is also to be noted that omitting the last step of this treatment (sonication in deionized water) leads to an increase in the number of sputtering/annealing cycles needed to obtain a surface of comparable purity. 


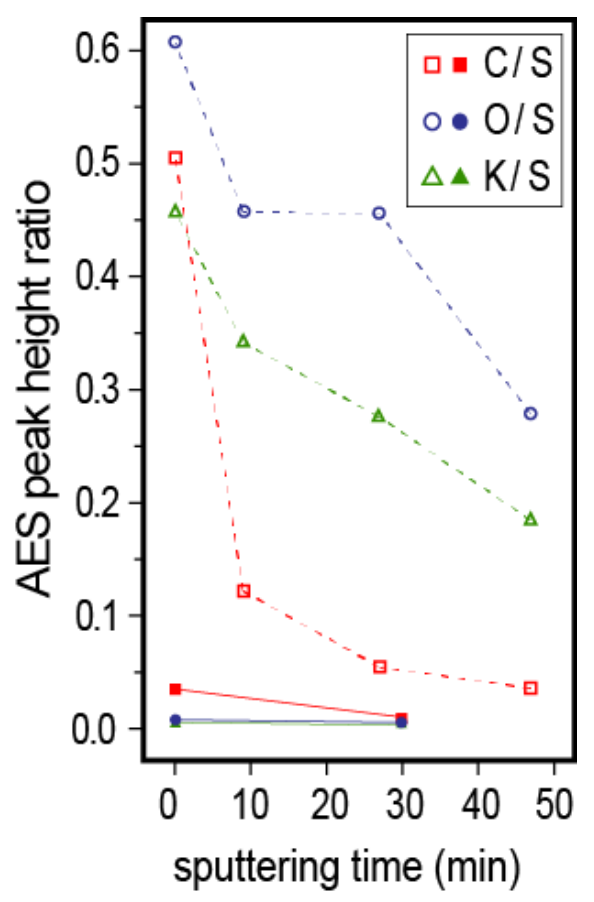

Figure 4. $\mathrm{C}_{275 \mathrm{ev}}, \mathrm{O}_{510 \mathrm{ev}}$ and $\mathrm{K}_{252 \mathrm{ev}}$ AES peak-peak heights ratio to $\mathrm{S}_{153 \mathrm{ev}}$, as a function of sputtering time without (hollow) and with (solid) acid treatment.

Annealing the $\mathrm{FeS}_{2}\{100\}$ surface at $600 \mathrm{~K}$ for 1 hour after removing surface contaminants according to this protocol produces a sharp and intense (1x1) LEED pattern with low diffuse background, as shown in Fig. 3c. This cleaning protocol significantly reduces the $\mathrm{He}^{+}$sputtering time (30 min) required to produce a clean $\mathrm{FeS}_{2}\{100\}$ surface with contaminant levels comparable to previous reports, which typically require over 100 min sputtering time [26-28, 32]. The resulting sharp LEED pattern also indicates a high degree of crystallographic order of the $\mathrm{FeS}_{2}\{100\}$ surface, which is of great relevance in order to obtain meaningful information of pristine pyrite surfaces using surface science methods. Furthermore, no obvious intensity change was observed in the LEED patterns obtained over several hours, indicating that the surface is not electron-beam sensitive, in contrast to pyrite surfaces prepared by cleaving under vacuum $[\underline{30}, \underline{31]}$.

\subsection{Preferential removal of sulphur}

Long term sputtering using either $\mathrm{Ar}^{+}$or $\mathrm{He}^{+}$at $200 \mathrm{eV}$ or $500 \mathrm{eV}$ induces irreversible severe 
crystallographic disorder on $\mathrm{FeS}_{2}\{100\}$ surfaces [30, $\underline{31]}$. The eventual loss of all LEED pattern shows that sputtering damage cannot be repaired by subsequent lengthy annealing. To study the effect of sputtering on the pyrite stoichiometric composition, we subjected a clean surface to $500 \mathrm{eV} \mathrm{He}^{+}$ sputtering. S/Fe AES peak ratios of the $\mathrm{FeS}_{2}\{100\}$ surface are plotted with increasing sputtering time in Fig. 5. In contrast to the procedure followed in compiling the data for Fig. 2, the surface composition was monitored after several successive periods of sputtering cycles without intervening anneals, and therefore the comparison is merely qualitative. The introduction of occasional 10 minute anneals to $600 \mathrm{~K}$, in order to study stoichiometric variations associated with surface damage reparation is indicated with arrows.

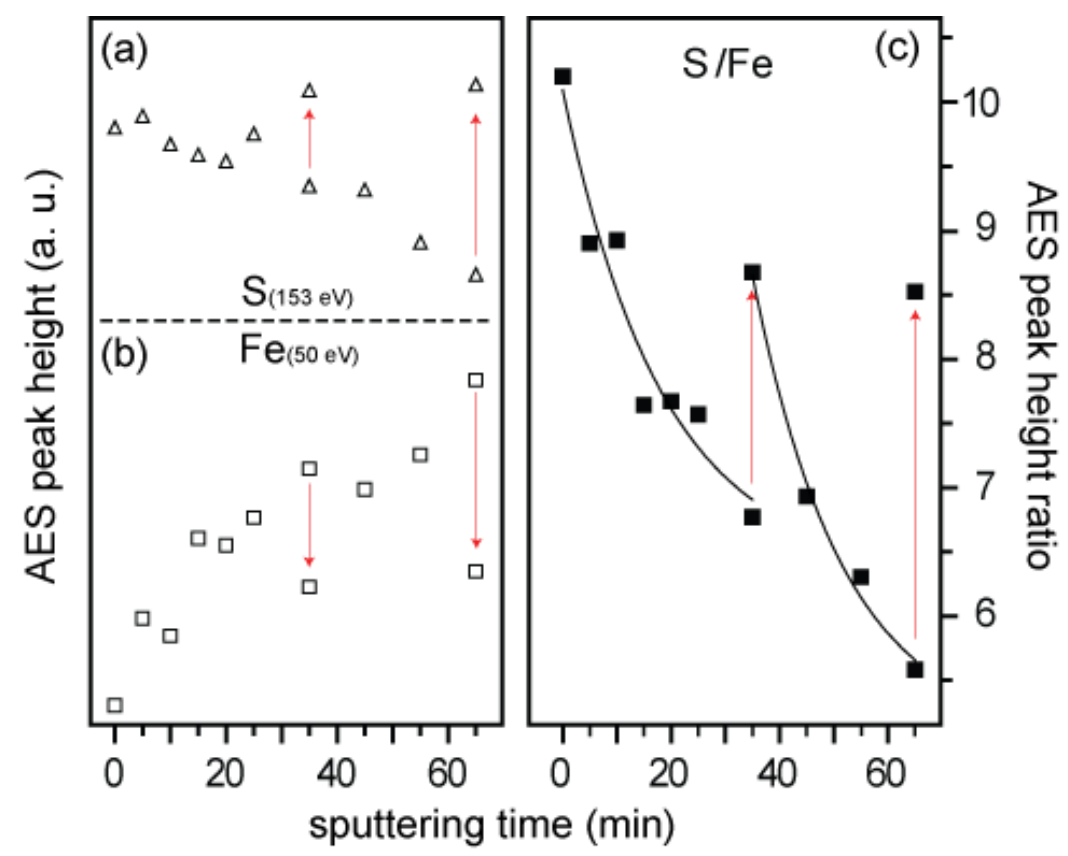

Figure 5. AES peak heights for $\mathrm{S}_{(153 \mathrm{eV})}(\mathrm{a}), \mathrm{Fe}_{(50 \mathrm{eV})}$ (b) and the $\mathrm{S} / \mathrm{Fe}$ ratio (c) against total sputtering time. Arrows indicate the response of AES peak heights and Fe/S ratio to 10 minutes annealing at $600 \mathrm{~K}$.

Fig. 5a, shows that sulphur AES peak height decreases, whereas iron AES peak height in Fig. 5b increases with sputtering time. As a result, a decrease in the $\mathrm{S} / \mathrm{Fe}$ ratio with longer cumulative sputtering times is clearly observed in Fig. 5c. This reduction in $\mathrm{S} / \mathrm{Fe}$ ratio is associated with the preferential depletion of sulphur by ion bombardment $[\underline{32}, \underline{34}]$, whereby the attenuation of Fe Auger electron intensity by $\mathrm{S}$ atoms is alleviated. 
Fig. 5 also shows that upon 10 minute anneals (indicated by arrows) the intensity of the Sulphur AES peak recovered almost completely (Fig. 5a), whilst Fe peak intensity reduces (Fig. 5b). As a consequence $\mathrm{S} / \mathrm{Fe}$ ratios increase, although not to the original values (Fig. 5c), indicating a cumulative sulphur deficit at the surface. The obvious interpretation of these results is that sulphur diffuses from the selvedge region to the depleted surface upon heating, but not to the extent to completely restore the stoichiometry of the pristine crystal. Sputtering damage therefore accumulates after each cycle of $\mathrm{He}^{+}$bombardment and 10 minute annealing, which eventually causes significant changes of the surface structure and the loss of the LEED pattern. In comparison with the case shown in Fig. 2b, energetic $\mathrm{He}^{+}$sputtering with much shorter and less frequent annealing cycles was applied here (Fig. 5). As a result, the surface $S$ was preferentially removed without sufficient bulk replenishment and therefore, lower S/Fe ratios $(<10)$ were observed than the steady state value in Fig. 2b ( 15).

It is clear that minimizing the number of sputter/anneal cycles needed to clean pyrite surfaces in vacuo reduces the structural damage generated by surface sulphur depletion. The ex situ acid pre-treatment reported here greatly reduces the need for high energy and long ion bombardment times, which impacts in in the control over the quality of the material. Furthermore this extends the life time of $\mathrm{FeS}_{2}$ crystals for surface science studies as it reduces the rate at which cumulative damage develops. The recovery of the pristine stoichiometry upon annealing has also clear direct consequences on the chemistry of pyrite surfaces, and therefore it is of great importance for detailed surface science studies, such as the one reported here investigating the chemistry of $\mathrm{FeS}_{2}\{100\}$ towards ammonia synthesis.

\section{Adsorption and reaction of nitrogen on clean $\mathrm{FeS}_{2}\{100\}$}

In order to establish the chemistry of iron sulphide towards ammonia synthesis from atmospheric nitrogen and hydrogen, the reactivity of $\mathrm{FeS}_{2}\{100\}$ towards $\mathrm{N}_{2}$ and $\mathrm{H}_{2}$ gas adsorption was studied before turning to co-adsorption experiments. Here we present a summary of our work, some of it previously published [24, 25] but described here with additional detail, on the adsorption characteristics and reaction upon 
coadsorption of these species on clean $\mathrm{FeS}_{2}\{100\}$. We also present preliminary work on biomimetic approaches to improve the characteristics of this material towards the activation of adsorbed $\mathrm{N}_{2}$.

\subsection{Background gas exposure to nitrogen}

Exposure of a clean "pristine" $\mathrm{FeS}_{2}\{100\}$ surface to molecular nitrogen gas at temperatures between 165 $\mathrm{K}$ and $450 \mathrm{~K}$ results in undetectable amounts of nitrogen adsorption either from Auger electron spectroscopy (AES) or temperature programmed desorption (TPD) experiments. This suggests that neither molecular adsorption nor dissociative chemisorption occur to any significant extent above $165 \mathrm{~K}$ at pressures up to 1 bar. By contrast $\mathrm{N}_{2}$ was found to adsorb on $\mathrm{FeS}_{2}\{100\}$ at lower temperatures under UHV conditions. Fig. 6 shows TPD spectra corresponding to $\mathrm{m} / \mathrm{z}=28(\mathrm{~m} / \mathrm{z}=14$ was also monitored to confirm $\mathrm{N}_{2}$ assignment) after $\mathrm{N}_{2}$ background exposure $(150 \mathrm{~L})$ at a surface temperature of $108 \mathrm{~K}$. The observed $\mathrm{N}_{2}$ desorption spectra has a maximum desorption rate at $130 \mathrm{~K}$ independently of exposure, consistent with first-order desorption kinetics [24]. The characteristics and low temperature of this peak suggest that this desorption pattern correspond to chemisorbed molecular nitrogen species $\left(\mathrm{N}_{2, \text { ads }}\right)$. This diagnosis was confirmed through isotopic exchange experiments in which exposure to ${ }^{14} \mathrm{~N}_{2}$ followed equal exposure to ${ }^{15} \mathrm{~N}_{2}$, and vice versa [24]. No evidence of isotopic exchange $(\mathrm{m} / \mathrm{z}=29)$, was observed under these conditions, confirming the non-dissociative nature of molecular $\mathrm{N}_{2}$ adsorption at low temperatures on $\mathrm{FeS}_{2}\{100\}$. 


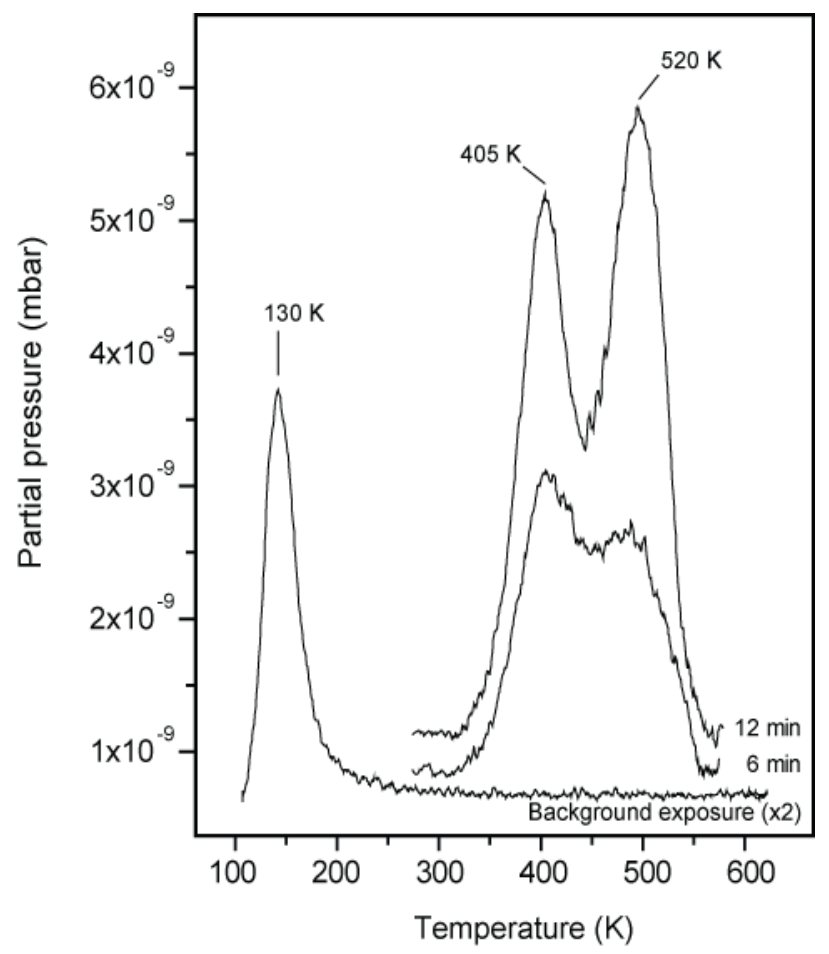

Figure 6. TPD spectra for $\mathrm{m} / \mathrm{z}=28$ obtained after background exposure of $\mathrm{FeS}_{2}\{100\}$ to $150 \mathrm{~L}$ of $\mathrm{N}_{2}$ at $108 \mathrm{~K}$, and 6 and 12 minutes exposure to activated neutral nitrogen species at 300K.

\subsection{Exposure to activated nitrogen species}

In order to promote the adsorption of nitrogen, $\mathrm{FeS}_{2}\{100\}$ was exposed to excited neutral nitrogen species generated by passing nitrogen gas through an ion source. Ions so generated and accelerated towards the target surface with a nominal kinetic energy of $500 \mathrm{eV}$ were discriminated by applying a positive bias potential of $+600 \mathrm{~V}$ to the sample. At this potential, all charged particles in the accelerated beam (whether singly or multiply charged) ought to be repelled before impact with the target surface, and therefore any adsorption is expected to result from incident activated neutral species.

Besides TPD spectra for $150 \mathrm{~L}$ of background exposure to $\mathrm{N}_{2}$ at low temperatures (spectrum multiplied $\mathrm{x}$ 2), Fig. 6 shows desorption spectra for $\mathrm{m} / \mathrm{z}=28$ after exposing a pyrite crystal to activated neutral nitrogen species for 6 and 12 minutes at $300 \mathrm{~K}$. This analysis allows a direct comparison of the intake and characteristics of adsorbed species both exposure methods produce. Whilst background exposure to 
molecular nitrogen at low temperature generates a small intake of weakly adsorbed molecular species, exposure to activated nitrogen at $300 \mathrm{~K}$ shows a relatively large intake of much strongly bonded species. Two features with maxima at 405 and $520 \mathrm{~K}$ can be seen in the $\mathrm{m} / \mathrm{z}=28$ desorption spectra under these conditions, with the $520 \mathrm{~K}$ feature becoming dominant with higher exposure times. Isotopic exchange experiments using this method show recombinative desorption of surface species at both 405 and $520 \mathrm{~K}$, indicating the presence of atomic nitrogen adsorbates on $\operatorname{FeS}_{2}\{100\}$ upon exposure to activated species [24].

The presence of two distinct desorption peaks in Fig. 6 corresponds to (at least) two distinct $\mathrm{N}_{\mathrm{ads}}$ species of different stability. Variations in the relative intensities of these desorption peaks with exposure time are accompanied by progressive loss of the (1x1) LEED pattern corresponding to the pristine $\mathrm{FeS}_{2}\{100\}$ surface, as well as a decrease in AES S/Fe ratio [24]. This indicates that this exposure method induces some degree of crystallographic damage and stoichiometric variation, relating the distinct adsorbed species to different local environments in the surface region. The increase in relative intensity of the 520 $\mathrm{K}$ desorption peak, alongside the progressive loss in LEED diffraction beams with increasing exposures suggest that species desorbing at this temperature may arise from defect sites. A high relative intensity of this desorption peak is also associated with low $\mathrm{S} / \mathrm{Fe}$ ratios in Auger spectra, consistent with desorption of $\mathrm{N}_{2}$ at $520 \mathrm{~K}$ arising from sulphur deficient sites. Similarly, the higher intensity of desorption at $405 \mathrm{~K}$ at lower exposures with sharper LEED patterns and higher S/Fe ratios, closer to pristine surface conditions, points at the presence of species adsorbed on non-defective sites [24]. These observations suggest that $\mathrm{N}_{\text {ads }}$ species may desorb from interstitial sites at $405 \mathrm{~K}$, and from substitutional sites (with $\mathrm{N}_{\text {ads }}$ species occupying sulphur vacancy positions) at $520 \mathrm{~K}$.

\subsection{Adsorption of hydrogen}

Fig. 7 shows TPD spectra obtained after exposing pristine pyrite to $1500 \mathrm{~L}$ of $\mathrm{H}_{2}$ at $170 \mathrm{~K}$. The presence of an incandescent Ta filament with line-of-sight to the sample was found to be essential to induce hydrogen adsorption at pressures up to 1 bar. Under these conditions a desorption feature in the $\mathrm{m} / \mathrm{z}=2$ 
spectrum at $225 \mathrm{~K}$ reveals that hydrogen readily adsorbs on $\mathrm{FeS}_{2}\{100\}$. However, the more intense desorption feature upon exposure to hydrogen gas corresponds to the $\mathrm{m} / \mathrm{z}=34$ spectrum, indicating desorption of $\mathrm{H}_{2} \mathrm{~S}$ at $260 \mathrm{~K}$. UHV studies commonly feature hot-filament ionization gauges to measure the pressure, and it is well understood that $\mathrm{H}_{2}$ dissociates at incandescent filaments [34, 35]. This suggest that it is in fact atomic $\mathrm{H}$ produced at the surface of the Ta filament, rather than molecular $\mathrm{H}_{2}$, that adsorbs on $\mathrm{FeS}_{2}\{100\}$ under these experimental conditions.

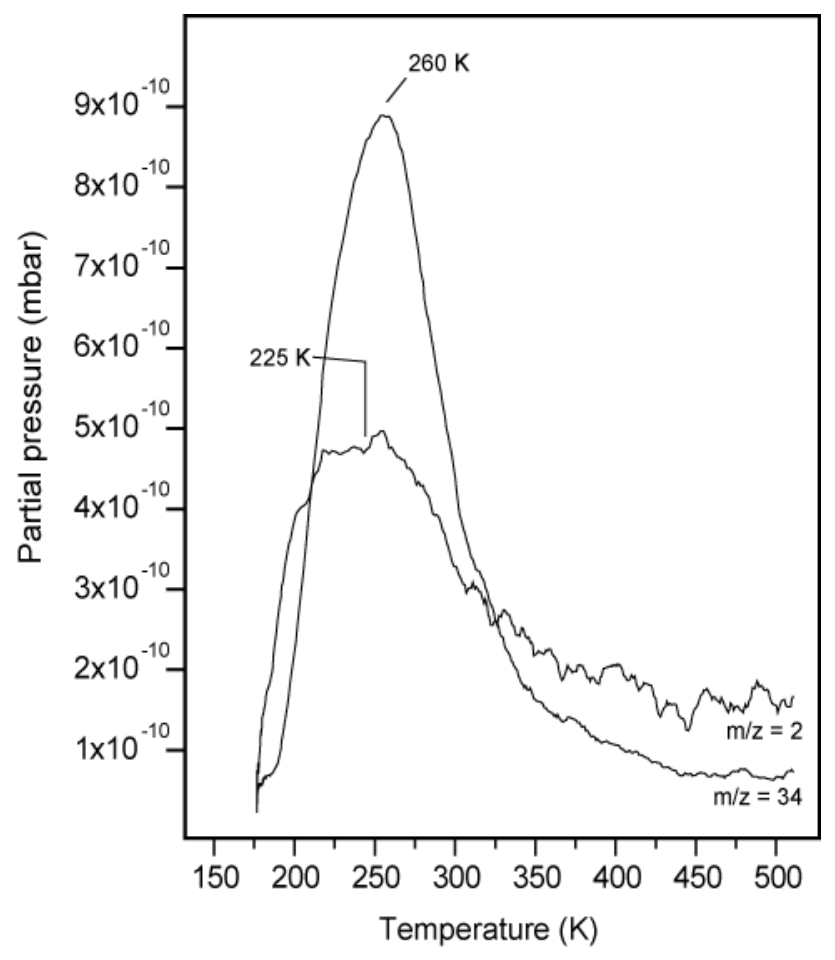

Figure 7. TPD spectra recorded for $\mathrm{m} / \mathrm{z}=2\left(\mathrm{H}_{2}\right)$ and $\mathrm{m} / \mathrm{z}=34\left(\mathrm{H}_{2} \mathrm{~S}\right)$ after exposing a clean $\mathrm{FeS}_{2}\{100\}$ surface at $170 \mathrm{~K}$ to $1500 \mathrm{~L}$ of hydrogen in the presence of an incandescent filament.

The presence of a feature corresponding to $\mathrm{H}_{2} \mathrm{~S}$ in the TPD spectra is indicative of an associative desorption process of atomic hydrogen adsorbates $\left(\mathrm{H}_{\mathrm{ads}}\right)$. This was confirmed through isotopic exchange experiments, in which the surface was sequentially exposed to $\mathrm{H}_{2}$ and $\mathrm{D}_{2}$, producing desorption features for both $\mathrm{m} / \mathrm{z}=3$ (HD) and $\mathrm{m} / \mathrm{z}=35$ (HDS) [25]. The desorption temperatures of $\mathrm{H}_{2}$ and $\mathrm{H}_{2} \mathrm{~S}$ do not vary with coverage, as would be expected for simple second-order recombinative desorption, suggesting that a significant amount of hydrogen may diffuse into the selvedge, forming a subsurface reservoir. The 
reaction of adsorbed hydrogen with lattice sulphur generate $\mathrm{S}$ vacancies on the initially pristine surface, which reflects in a loss of intensity in the $\mathrm{FeS}_{2}\{100\}$ LEED pattern with increasing exposures [25].

\subsection{Ammonia synthesis}

Fig. 8 shows temperature programmed reaction (TPR) spectra corresponding to $\mathrm{m} / \mathrm{z}=14(\mathrm{~N}), \mathrm{m} / \mathrm{z}=17$ $\left(\mathrm{NH}_{3}\right)$, and $\mathrm{m} / \mathrm{z}=34\left(\mathrm{H}_{2} \mathrm{~S}\right)$ after $\mathrm{N}_{\mathrm{ads}}$ and $\mathrm{H}_{\mathrm{ads}}$ were sequentially preadsorbed on $\mathrm{FeS}_{2}\{100\}$ at $170 \mathrm{~K}$. Masses corresponding to $\mathrm{m} / \mathrm{z}=16$ and $\mathrm{m} / \mathrm{z}=18$ were also monitored, primarily to discriminate the possible desorption of $\mathrm{H}_{2} \mathrm{O}$ from the $\mathrm{m} / \mathrm{z}=17$ spectrum. Activated nitrogen species were dosed through an ion gun for 10 minutes while the target surface was held at $+600 \mathrm{~V}$ bias potential to ensure complete deflection of charged particles, as described above. After a period of time sufficient for UHV conditions to be reinstated, the surface was exposed to an equivalent of $1500 \mathrm{~L}$ of hydrogen gas (in the presence of an incandescent Ta filament). TPR spectra for the above-mentioned $\mathrm{m} / \mathrm{z}$ channels was then recorded at a rate of $2 \mathrm{~K} / \mathrm{s}$, once the base pressure of the chamber was attained $\left(\sim 1 \times 10^{-10} \mathrm{mbar}\right)$.

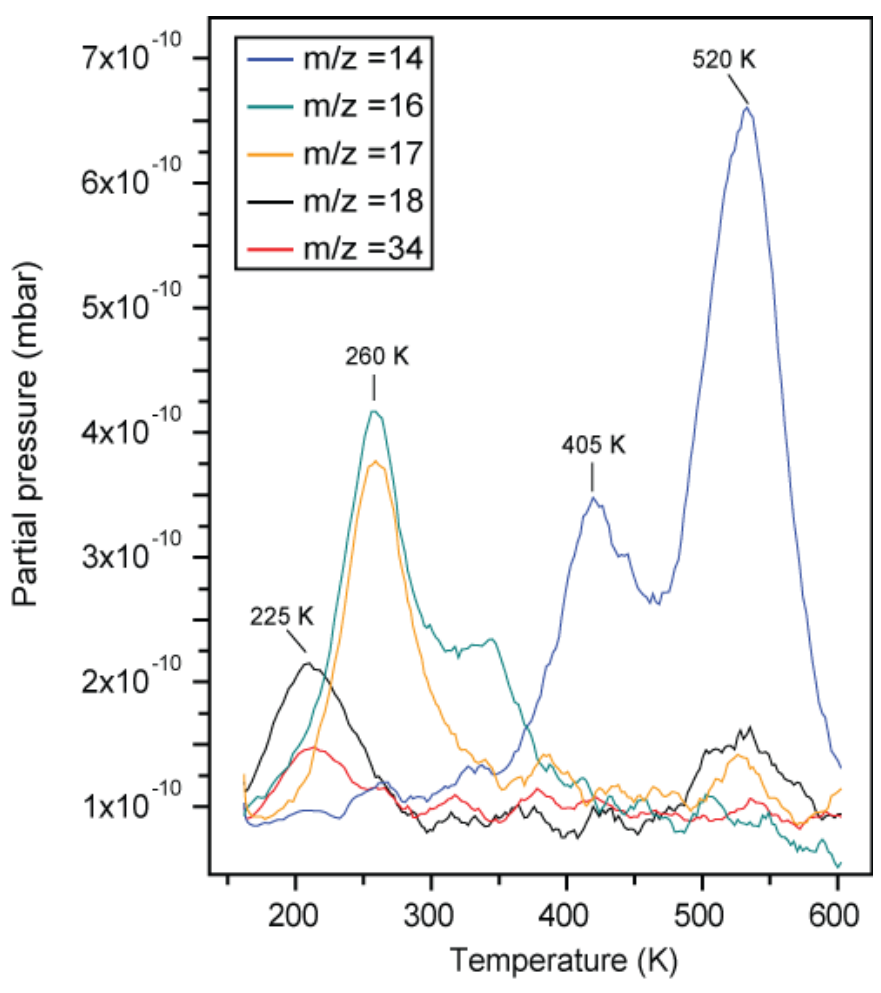


Figure 8 . TPR spectra for $\mathrm{m} / \mathrm{z}=14, \mathrm{~m} / \mathrm{z}=16, \mathrm{~m} / \mathrm{z}=17, \mathrm{~m} / \mathrm{z}=18$, and $\mathrm{m} / \mathrm{z}=34$ after sequentially exposing a clean $\mathrm{FeS}_{2}\{100\}$ surface at $170 \mathrm{~K}$ to activated nitrogen species (10 minutes) followed to exposure to $1500 \mathrm{~L}$ of hydrogen.

Under these experimental conditions a desorption peak for $\mathrm{m} / \mathrm{z}=17$ (as well as $\mathrm{m} / \mathrm{z}=16$ ) arises corresponding to the formation and desorption of $\mathrm{NH}_{3}$ at $230 \mathrm{~K}$. Fig. 8 also shows desorption features for $\mathrm{m} / \mathrm{z}=14$ corresponding $\mathrm{N}_{2}$ recombinative desorption at 405 and $520 \mathrm{~K}$, indicating incomplete reaction. Small quantities of $\mathrm{H}_{2} \mathrm{~S}(\mathrm{~m} / \mathrm{z}=34)$ and $\mathrm{H}_{2} \mathrm{O}(\mathrm{m} / \mathrm{z}=18)$ are also desorbed under these conditions at $225 \mathrm{~K}$. The $\mathrm{H}_{2} \mathrm{~S}$ desorption temperature is slightly lower than that seen for the adsorption of hydrogen in the absence of $\mathrm{N}_{\mathrm{ads}}(260 \mathrm{~K})$, which suggests a certain degree of surface disorder [25]. This observation is consistent with LEED data obtained after surface exposure to activated nitrogen species showing a mild degradation of the pristine (1x1) diffraction pattern [24]. Formation and desorption of $\mathrm{H}_{2} \mathrm{~S}$ and $\mathrm{H}_{2} \mathrm{O}$ occurs as a consequence of competitive reactions, however the relative amounts of $\mathrm{H}_{2} \mathrm{~S}, \mathrm{H}_{2} \mathrm{O}$ and $\mathrm{NH}_{3}$ produced reveal a clear preference for hydrogen to react with $\mathrm{N}_{\mathrm{ads}}$ rather than with lattice sulphur or oxygen species.

Fig. 9b displays TPR area analysis of the two $\mathrm{N}_{2}(\mathrm{~m} / \mathrm{z}=28)$ desorption peaks at $405 \mathrm{~K}$ and $520 \mathrm{~K}$, and the corresponding $\mathrm{NH}_{3}(\mathrm{~m} / \mathrm{z}=17)$ desorption peak at $260 \mathrm{~K}$ as a function of $\mathrm{H}_{2}$ exposures. Initially, the 405 $\mathrm{K}$ peak, associated to $\mathrm{N}_{2}$ desorption from interstitial sites, decreases progressively with increasing the $\mathrm{H}$ exposure, disappearing altogether above $4600 \mathrm{~L}$ nominal exposure (Fig. 9a). On the other hand, the area of the $520 \mathrm{~K}$ peak (Fig. 9a), attributed to $\mathrm{N}_{2}$ desorption from sulphur deficient sites, is nearly constant with increasing hydrogen exposure. This observation suggests that nitrogen adsorbed at non-defective sites readily react with hydrogen, whereas only a small fraction of nitrogen at the defective sites can react under these conditions. The implication of these observations is that iron atoms at sulphur deficient sites may bond more strongly with nitrogen (as a higher desorption temperature indicates), but a small fraction of these species are still capable of undergo hydrogenation to form ammonia at $260 \mathrm{~K}$. 

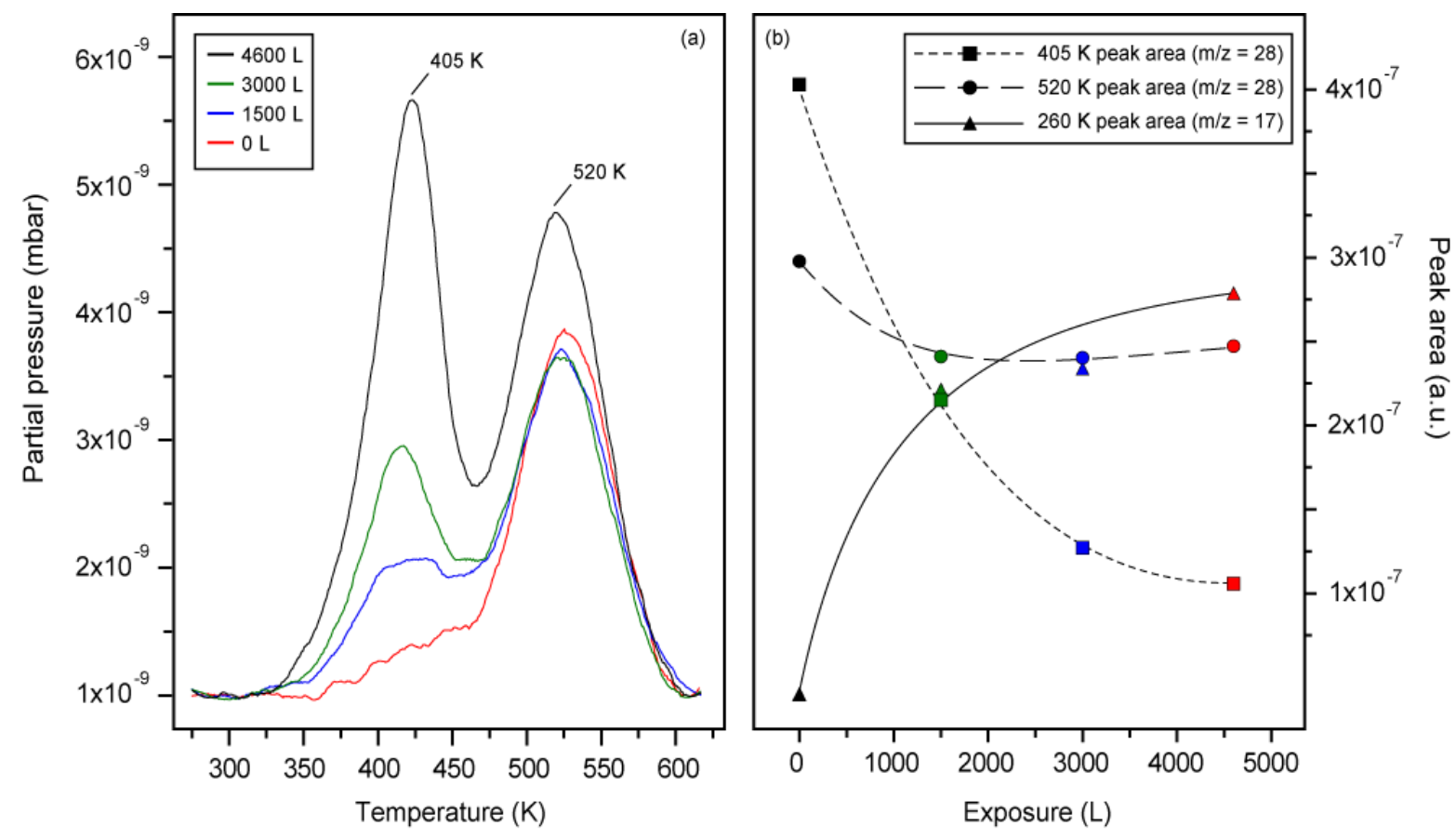

Figure 9. (a) Series of TPR spectra for $\mathrm{m} / \mathrm{z}=28$ with increasing hydrogen exposure; (b) Peak area intensities for the $405 \mathrm{~K}$ (squares) and $520 \mathrm{~K}$ (circles) features of the $\mathrm{m} / \mathrm{z}=28 \mathrm{TPR}$ spectra $\left(\mathrm{N}_{2}\right)$, and 260 $\mathrm{K}$ (triangles) of the $\mathrm{m} / \mathrm{z}=17\left(\mathrm{NH}_{3}\right)$ as function of hydrogen exposure. Visual evolution traces have been placed for ease of reference.

These results show that it is possible to produce $\mathrm{NH}_{3}$ from adsorbed $\mathrm{N}_{\text {ads }}$ and $\mathrm{H}_{\text {ads }}$ on pyrite crystals under low pressure conditions. Crucially these results also indicate that hydrogenation and desorption of $\mathrm{NH}_{3}$ occur below room temperature under the tested experimental conditions. Nevertheless, it is clear from these results that highly energetic excited species are required to form the necessary $\mathrm{N}_{\text {ads }}$ species on $\mathrm{FeS}_{2}\{100\}$ to produce $\mathrm{NH}_{3}$. In order to investigate possible influences of composition and morphology in the capacity of pyrite to adsorb atmospheric $\mathrm{N}_{2}$ we have preliminarily explored various strategies inspired $y$ the characteristics of the enzymatic Mo-cofactor.

\section{Mo deposition on $\mathrm{FeS}_{2}\{100\}$}


Iron sulphide clusters in nitrogenases commonly present a transition metal atom (typically molybdenum) at its edge, believed to influence the adsorption and stability of $\mathrm{N}_{2}[\underline{8-13}]$. It has been proposed that the presence of an apex Mo atom (instead of a Fe atom) increases the activity of the FeMo-cofactor by lowering the energy barrier of the rate-limiting step, the hydrogenation of $\mathrm{N} \equiv \mathrm{N}$ to $\mathrm{N}=\mathrm{NH}$ [20]. In general, to facilitate the first hydrogenation step, one could certainly seek to weaken the intramolecular bond of $\mathrm{N}_{2}$ by electron donation to the empty $2 \pi^{*}$ antibonding orbital on $\mathrm{N}_{2, \text { ads }}$ species. However, interactions dominated by electron back-filling from metallic surfaces to the molecular $2 \pi^{*}$ orbital usually lead to $\mathrm{N}_{2}$ dissociation, e.g., $\mathrm{N}_{2} / \mathrm{Fe}\{111\}$ [36]. Consequently $\mathrm{NH}_{3}$ synthesis on such metal surfaces proceeds via hydrogenating atomic $\mathrm{N}_{\text {ads. }}$. In order to investigate the influence of transition metals to the chemistry of pyrite towards the formation of ammonia we studied the deposition of Mo on $\mathrm{FeS}_{2}\{100\}$ and the reactivity of the resulting surface towards nitrogen and hydrogen adsorption.

\subsection{Molybdenum deposition}

Molybdenum accretion was effectuated by electron-beam deposition on a clean $\mathrm{FeS}_{2}\{100\}$ surface at 170 K. Mo coverage was controlled by varying the evaporation time, (0-25 minutes) while maintaining a constant evaporation flux ( $25 \mu \mathrm{A})$. Typically, at the end of each deposition step a flash anneal to $600 \mathrm{~K}$ (at $10 \mathrm{Ks}^{-1}$ ) was performed to allow surface reconstruction.

AES data in Fig. 12a shows the appearance of new peaks on the pyrite spectrum at 190 and $225 \mathrm{eV}$, corresponding to molybdenum, with growing intensity with exposure times. The appearance of new Mo peaks is associated with a decrease in intensity of the sulphur and iron peaks, suggesting that molybdenum built up is occurring on the $\mathrm{FeS}_{2}\{100\}$ surface, hence masking the AES signals from the underlying pyrite crystal. Fig. 10b displays the Mo/S peak ratios following a stepwise electron-beam deposition of Mo at $170 \mathrm{~K}$, followed by flash anneal to $600 \mathrm{~K}$ after each step. Initial expected rise of $\mathrm{Mo} / \mathrm{S}$ ratios after exposure to Mo (red circles) is followed by a small drop following flash anneal (black squares), indicating that sulphur concentration at the Mo-covered surface increases upon annealing. Fig. 10c shows a relatively modest decrease in the Fe/S AES ratios upon Mo deposition (red circles) which 
could arise from a higher masking effect on the Fe $50 \mathrm{eV}$ peak than on the $\mathrm{S} 153 \mathrm{eV}$ upon Mo built up. A much larger effect though is caused by annealing of the Mo covered $\mathrm{FeS}_{2}\{100\}$ surface, suggesting that while Fe remains under the layer of newly deposited Mo, S diffuses to the upmost layer forming a new $\mathrm{MoS}_{\mathrm{x}}$ surface.
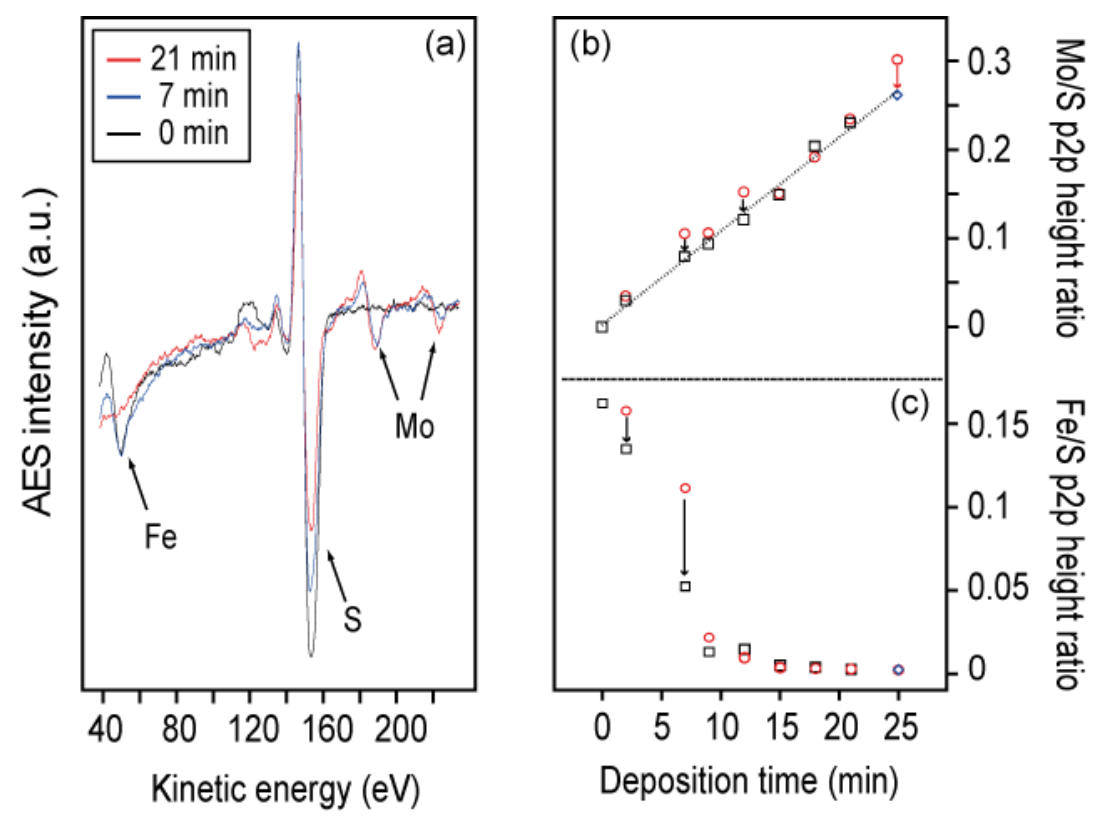

Figure 10. (a) Auger spectra following increasing Mo deposition times, recorded after a flash anneal to $600 \mathrm{~K}$ in each case; (b) $\mathrm{Mo}_{190 \mathrm{ev}} / \mathrm{S}_{155 \mathrm{eV}}$ and (c) $\mathrm{Fe}_{50 \mathrm{ev}} / \mathrm{S}_{155 \mathrm{ev}}$ Auger peak height ratios as a function of Mo deposition time. In each case data was recorded prior to (red circles) and after (black squares) flash anneals to $600 \mathrm{~K}$.

Upon Mo accumulation on pyrite, LEED data shows a progressive loss in intensity of the (1x1) square pattern corresponding to the pristine $\mathrm{FeS}_{2}\{100\}$ surface, indicating that Mo builds up initially forming a disordered structural phase. In a previous article, we have shown that ordered layers of $\mathrm{MoS}_{2}\{0001\}$, characterized by an hexagonal LEED pattern replacing the square pattern of the pristine $\mathrm{FeS}_{2}\{100\}$ surface, can be formed by annealing the disordered Mo-covered pyrite crystal to $600 \mathrm{~K}$ for longer periods [37]. The formation of $\operatorname{MoS}_{2}\{0001\}$ on $\mathrm{FeS}_{2}\{100\}$ is attributed to (i) the diffusion of $\mathrm{S}$ from the pyrite crystal bulk during annealing; (ii) the high thermodynamic driving force of S to react with Mo; and (iii) 
the approximate lattice match of the common element (sulphur) between $\operatorname{MoS}_{2}\{0001\}$ and $\mathrm{FeS}_{2}\{100\}$ structures [37]. This ordered $\operatorname{MoS}_{2}\{0001\}$ structure, however, does not grow indefinitely with increasing Mo deposition and annealing. Instead, a disordered Mo layer forms on top of the initially grown $\operatorname{MoS}_{2}\{0001\}$ layer with longer exposure times, even after long anneals [37].

\subsection{Background gas exposure to nitrogen}

After establishing a protocol to produce and characterize a range of coverages of molybdenum on a $\mathrm{FeS}_{2}\{100\}$ surface, we investigated their activity towards the adsorption of nitrogen through background exposure to $\mathrm{N}_{2}$.

Exposing Mo-covered $\mathrm{FeS}_{2}\{100\}$ (with or without a subsequent annealing) to $\mathrm{N}_{2}$ gas under UHV conditions showed no evidence of nitrogen adsorption, either in AES or TPD. Nor was such evidence observed (using AES) in high pressure experiments, in which the Mo-covered pyrite crystal was exposed at $300 \mathrm{~K}$ to up to 1 bar of $\mathrm{N}_{2}$ gas for 30 minutes. Auger measurements corresponding to these conditions merely showed slight carbon contamination on the surface, but no sign of adsorbed nitrogen species.

Additional experiments, in which an $\mathrm{FeS}_{2}\{100\}$ surface heavily damaged by $\mathrm{He}^{+}$sputtering (no diffracted beams visible in LEED) exposed to different amounts of Mo, did not exhibit observable increase in the capability of adsorbing $\mathrm{N}_{2}$. These experiments were performed under either UHV or high pressure (up to 1 bar) and temperatures ranging between $125 \mathrm{~K}$ and $300 \mathrm{~K}$. These results suggest that neither molecular adsorption nor dissociative chemisorption of $\mathrm{N}_{2}$ occurs to any significant extent measurable under the above conditions on Mo-deposited pyrite surfaces. This conclusion holds at both low or high molybdenum coverages, as well as on ordered and disordered $\operatorname{MoS}_{\mathrm{x}}$ overlayers on $\mathrm{FeS}_{2}\{100\}$.

$\mathrm{FeS}_{2}\{100\}$ is generally considered to be a relatively inert surface. Molybdenum, on the other hand, readily dissociates $\mathrm{N}_{2}$ under UHV conditions, with relatively high initial sticking probabilities at $300 \mathrm{~K}$ $\left[\underline{38}, \underline{39}\right.$. Nevertheless, dissociative adsorption of $\mathrm{N}_{2}$, at pressures up to 1 bar between $170 \mathrm{~K}$ and $300 \mathrm{~K}$, was not observed on the Mo-deposited $\mathrm{FeS}_{2}\{100\}$ surface prepared without subsequent annealing. This 
suggests that the interaction of the deposited Mo with the pyrite substrate, most likely through sulphur diffusion, renders it incapable of dissociating $\mathrm{N}_{2}$ under the studied conditions. Upon annealing to $600 \mathrm{~K}$ a disordered $\mathrm{Mo} / \mathrm{FeS}_{2}$ surface, Mo interacts with further accessible sulphur segregating from the bulk pyrite crystal, readily forming an ordered $\mathrm{MoS}_{2}\{0001\}$ overlayer on the $\mathrm{FeS}_{2}\{100\}$ surface. This resulting surface is inert to $\mathrm{N}_{2}$ chemisorption, in line with the saturation of all available chemical bonds within each $\mathrm{MoS}_{2}$ tri-layer, and the fact that the basal plane of $\mathrm{MoS}_{2}\{0001\}$ is known to be extremely inert to gas adsorption $[\underline{40}, \underline{41}]$.

\subsection{Adsorption of hydrogen}

In the current work, the only technique available to confirm the adsorption of hydrogen is TPD, which inevitably involves annealing the Mo-covered pyrite crystal; this in turn segregates $S$ to the surface, leading to the formation of ordered $\mathrm{MoS}_{2}\{0001\}$ overlayers. Therefore, the results here reported for the interaction of hydrogen with the Mo-deposited pyrite crystal only apply to the $\operatorname{MoS}_{2}\{0001\} / \mathrm{FeS}_{2}\{100\}$ hybrid surfaces.

Fig. 11a shows TPD spectra for $\mathrm{m} / \mathrm{z}=2\left(\mathrm{H}_{2}\right)$ of varying exposures to hydrogen at $170 \mathrm{~K}$ under UHV conditions, in the presence of an incandescent filament, as a function of increasing Mo coverages. TPD data after $300 \mathrm{~L}$ hydrogen exposure on pristine pyrite shows a strong desorption of $\mathrm{H}_{2}$ at $225 \mathrm{~K}$, indicating a relative large intake of hydrogen. Hydrogen was also found to adsorb on $\operatorname{MoS}_{2}\{0001\} / \mathrm{FeS}_{2}\{100\}$ surfaces at low molybdenum content $(0.088-0.45 \mathrm{Mo} / \mathrm{S}$ peak AES ratios), with TPD spectra showing a shoulder at $350 \mathrm{~K}$ to the primary desorption peak at $225 \mathrm{~K}$. Increase in intensity of the desorption peak at $225 \mathrm{~K}$ with higher molybdenum contents in this regime indicates an increase in the uptake of hydrogen. $\mathrm{No}_{2}$ desorption was observed after exposure to hydrogen in the absence of an incandescent filament at any Mo content.

Fig. $11 \mathrm{~b}$ shows TPD spectra for $\mathrm{m} / \mathrm{z}=34\left(\mathrm{H}_{2} \mathrm{~S}\right)$ after exposure to hydrogen at $170 \mathrm{~K}$, in the presence of an incandescent filament, on pristine $\mathrm{FeS}_{2}\{100\}$ and $\operatorname{MoS}_{2}\{0001\} / \mathrm{FeS}_{2}\{100\}$ surfaces (no hexagonal LEED 
pattern; $0.04 \mathrm{Mo} / \mathrm{S}$ AES peak ratio). Desorption features in the TPD spectra, corresponding to $\mathrm{H}_{2} \mathrm{~S}$, at 260 $\mathrm{K}$ indicates recombinative desorption of hydrogen at various coverages of $\mathrm{MoS}_{2}\{0001\}$ on $\mathrm{FeS}_{2}\{100\}$. As in the case of Fig. 11a, no $\mathrm{H}_{2} \mathrm{~S}$ desorption was observed after exposure to hydrogen in the absence of an incandescent filament. The inability of $\operatorname{MoS}_{2}\{0001\} / \mathrm{FeS}_{2}\{100\}$ surfaces to undertake $\mathrm{H}_{2}$ dissociative chemisorption is consistent with the work by Farias et al. [41], in which the basal plane of $\operatorname{MoS}_{2}\{0001\}$ was found to be unreactive towards $\mathrm{H}_{2}$.
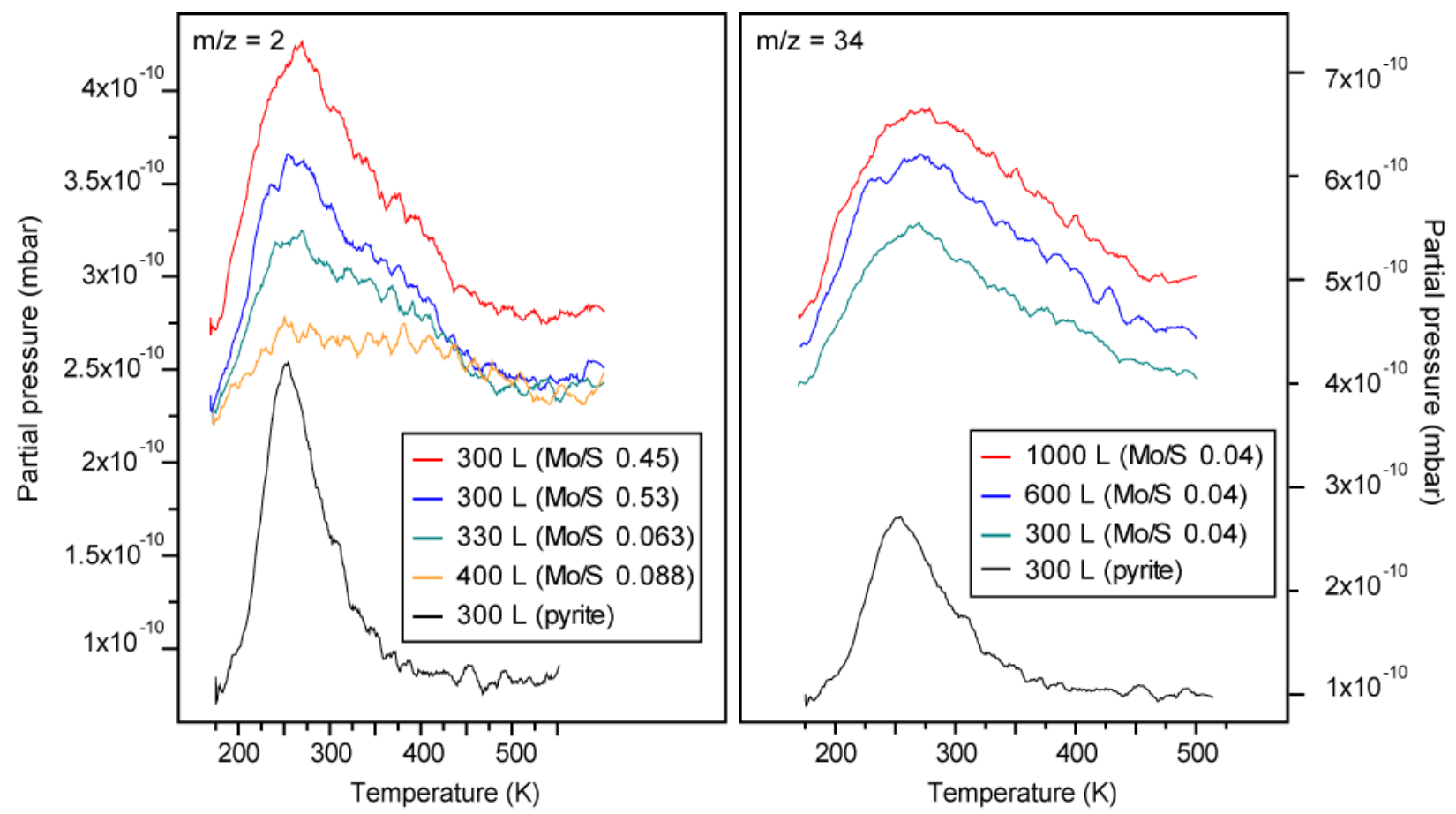

Figure 11. TPD spectra corresponding to (a) $\mathrm{m} / \mathrm{z}=2\left(\mathrm{H}_{2}\right)$ following various exposures to hydrogen at 175 $\mathrm{K}$ of a pristine $\mathrm{FeS}_{2}\{100\}$ surface, and increasing coverages of $\mathrm{MoS}_{2}\{0001\}$ on $\mathrm{FeS}_{2}\{100\}$ (represented as a function of the Mo/S AES peak ratios); and (b) m/z = $34\left(\mathrm{H}_{2} \mathrm{~S}\right)$ TPD spectra following increasing exposures of hydrogen on a pristine $\mathrm{FeS}_{2}\{100\}$ surface and $\mathrm{MoS}_{2}\{0001\} / \mathrm{FeS}_{2}\{100\}(0.04 \mathrm{Mo} / \mathrm{S} \mathrm{AES}$ peak ratio).

Besides the previously observed desorption features for $\mathrm{H}_{2}$ and $\mathrm{H}_{2} \mathrm{~S}$ at $225 \mathrm{~K}$ and $260 \mathrm{~K}$ respectively from pristine $\mathrm{FeS}_{2}\{100\}$ surfaces, the TPD spectra from the Mo-deposited pyrite surfaces in Fig. 11 exhibits additional desorption features at higher temperatures. This is more clearly illustrated in Fig. 11, in which 
similar desorption spectra for $\mathrm{H}_{2}$ and $\mathrm{H}_{2} \mathrm{~S}$ were obtained after exposing pyrite surfaces at higher coverages of $\mathrm{MoS}_{2}\{0001\}$ to equivalent amounts of hydrogen in the presence of an incandescent Ta filament. TPD data in Fig. 12b shows that as the surface coverage of $\mathrm{MoS}_{2}$ increases, evidenced by the evolution of increasingly intense hexagonal LEED pattern in the insert, a desorption feature of $\mathrm{H}_{2} \mathrm{~S}$ at $375 \mathrm{~K}$ emerges. This feature, initially appearing as a shoulder of original the $260 \mathrm{~K}$ peak, gradually becomes a dominant feature, while the $\mathrm{H}_{2} \mathrm{~S}$ desorption at $260 \mathrm{~K}$ clearly reduces in intensity. A similar effect is observed for the desorption spectra of $\mathrm{H}_{2}$ with a higher temperature broad desorption feature at 350-400 K growing with Mo coverage. In the case of the $\mathrm{H}_{2}$ desorption spectra this high temperature feature seems to broaden at high Mo coverages up to temperatures higher than $500 \mathrm{~K}$, suggesting desorption from interstitial hydrogen diffused in the bulk.

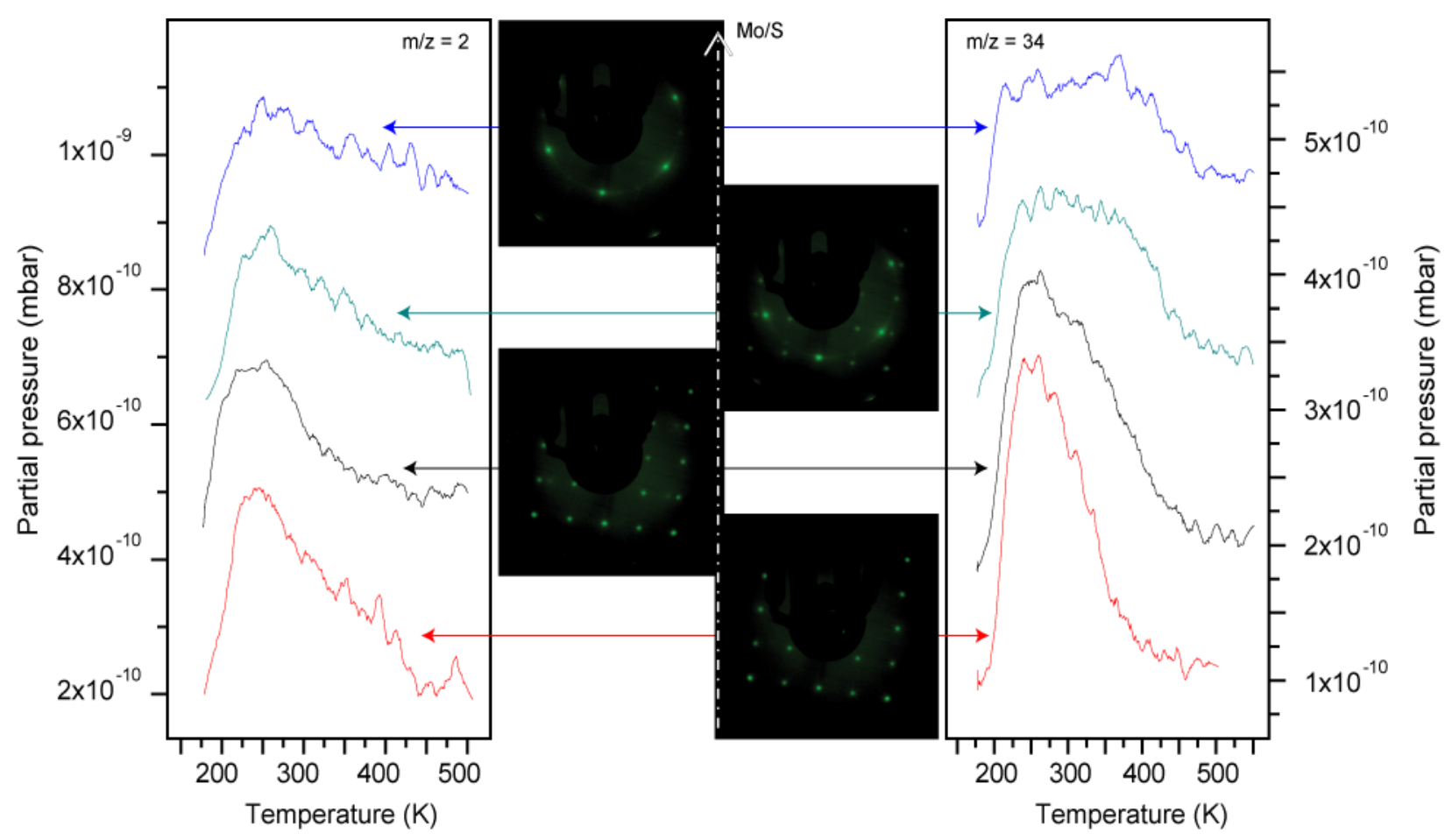

Figure 12. $\mathrm{H}_{2}$ and $\mathrm{H}_{2} \mathrm{~S}$ TPD spectra as a function of increasing Mo deposition on a clean $\mathrm{FeS}_{2}\{100\}$ surface, which was subsequently exposed at $170 \mathrm{~K}$ to equivalent amount of atomic $\mathrm{H}$ under UHV conditions; The surface structure prior to each $\mathrm{H}$ exposure was depicted in the LEED patterns. A total of 11-minute Mo was cumulatively deposited. 
Both the top LEED pattern in Fig. 12 and the corresponding Fe/S ratio (close to zero) in Auger measurements in Fig. 10c, suggest that under these conditions the proportion of uncovered pristine $\mathrm{FeS}_{2}\{100\}$ surface is negligible. Nevertheless $\mathrm{H}_{2}$ and $\mathrm{H}_{2} \mathrm{~S}$ desorption features at $225 \mathrm{~K}$ and $260 \mathrm{~K}$ respectively, corresponding to recombinative desorption from pristine $\mathrm{FeS}_{2}\{100\}$ surfaces, are observed under these conditions. Higher temperature desorption features at 350-400 K, and $375 \mathrm{~K}$ respectively are assigned to recombinative desorption from $\operatorname{MoS}_{2}\{0001\}$-related sites, where lattice $\mathrm{S}$ atoms are more stable than in $\mathrm{FeS}_{2}$ sites, and thus are only accessible to react with $\mathrm{H}_{\mathrm{ads}}$ at higher temperatures. To reconcile these apparently conflicting observations, is worth noting that LEED and AES electron beams probe cover areas of $\sim 1 \mathrm{~mm}^{2}$, whereas TPD measurements cover much larger areas $\left(\sim 30 \mathrm{~mm}^{2}\right.$ determined by the aperture size of the mass spectrometer shielding cone). The apparent discrepancy in the result is thus suspected to be caused by the heterogeneous deposition rate of the evaporator across the whole surface area. Although LEED patterns appear to be purely hexagonal in the central surface region, some low-intensity diffuse diffraction beams on square patterns, corresponding to $\operatorname{FeS}_{2}\{100\}$ regions, were indeed observed on the peripheral regions of the sample.

These results indicate that facile diffusion of $\mathrm{S}$ from the pyrite substrate effectively poisons deposited metallic Mo, preventing it from dissociating both $\mathrm{N}_{2}$ and $\mathrm{H}_{2}$ under the above experimental conditions.

\section{6. $\mathrm{Fe}_{\mathrm{x}} \mathrm{S}_{\mathrm{y}}$ Nanoparticles}

It has been suggested that part of the activity of the $\mathrm{Fe}_{\mathrm{x}} \mathrm{S}_{\mathrm{y}}$ nanocluster in the Mo-cofactor of nitrogenases stems from a size effect $[\underline{8}, \underline{11}, \underline{18}]$. It is thus logical to study the interaction of $\mathrm{N}_{2}$ and $\mathrm{H}_{2}$ with $\mathrm{Fe}_{\mathrm{x}} \mathrm{S}_{\mathrm{y}}$ nanoclusters of various sizes, and compare the results with those obtained for $\mathrm{FeS}_{2}\{100\}$ surfaces. We have therefore prepared $\mathrm{Fe}$ and $\mathrm{Fe}_{\mathrm{x}} \mathrm{S}_{\mathrm{y}}$ nanoclusters/thin films on an inert substrate $(\mathrm{Au}\{111\})$, to examine the characteristics of $\mathrm{N}_{2}$ adsorption on pyrite as a function of the cluster size.

The chemically inert close packed $\mathrm{Au}\{111\}$ surface is an ideal substrate for nucleation and growth of small clusters, in part due to the herringbone reconstruction [42], containing alternating regions of hep 
(hexagonal closed packed) and fcc (face centred cubic) stacking sequences. Midway between the hcp and fcc regions, Au atoms sit in bridge positions with respect to the second layer, running in a zig-zag manner across the surface, with a partial dislocation being situated at the turns of the zig-zag structure. It has been shown, by STM and LEED measurements, that $\mathrm{Fe}[43,44]$ and $\mathrm{Fe}_{\mathrm{x}} \mathrm{S}_{\mathrm{y}}[45]$ nanoclusters preferentially nucleate at these partial dislocations, and since the nucleation sites are some distance apart, well-separated nanoclusters can be formed on this inert substrate $[\underline{43}, \underline{44}]$. This substrate seems therefore ideal to perform experiments on the chemistry of $\mathrm{Fe}_{\mathrm{x}} \mathrm{S}_{\mathrm{y}}$ clusters, limiting the probability of sintering.

We have first investigated the formation of Fe clusters on an $\mathrm{Au}\{111\}$ surface at $300 \mathrm{~K}$ by electron-beam deposition. Fe exposure was controlled by varying the evaporation time, typically 0-20 minutes, while maintaining a constant evaporation flux $(\sim 15 \mu \mathrm{A})$. The amount of Fe present on the $\mathrm{Au}\{111\}$ after ebeam deposition was evaluated by AES. Fig. 13a displays AES spectra of a clean $\mathrm{Au}\{111\}$ surface with increasing $\mathrm{Fe}$ deposition times, showing a progressive decrease in intensity of Au peaks in the range between 40 and $300 \mathrm{eV}$, which indicates the presence of a masking agent on the surface. This reduction in the intensity of Au peaks is accompanied by the appearance and growth of Fe related peaks at 50, 600, 654, and $705 \mathrm{eV}$ for $\mathrm{Fe}$ deposition times between 0 and 20 minutes. Fig. 13b shows clearly the appearance and growth of the later 3 peaks in the $550-720 \mathrm{eV}$ region. These results confirms that $\mathrm{Fe}$ is successfully deposited on the $\mathrm{Au}\{111\}$ surface, with the complete disappearance of Au signals suggesting the surface Fe layer has become thicker than $\sim 1 \mathrm{~nm}$ after 20 minutes of deposition. 

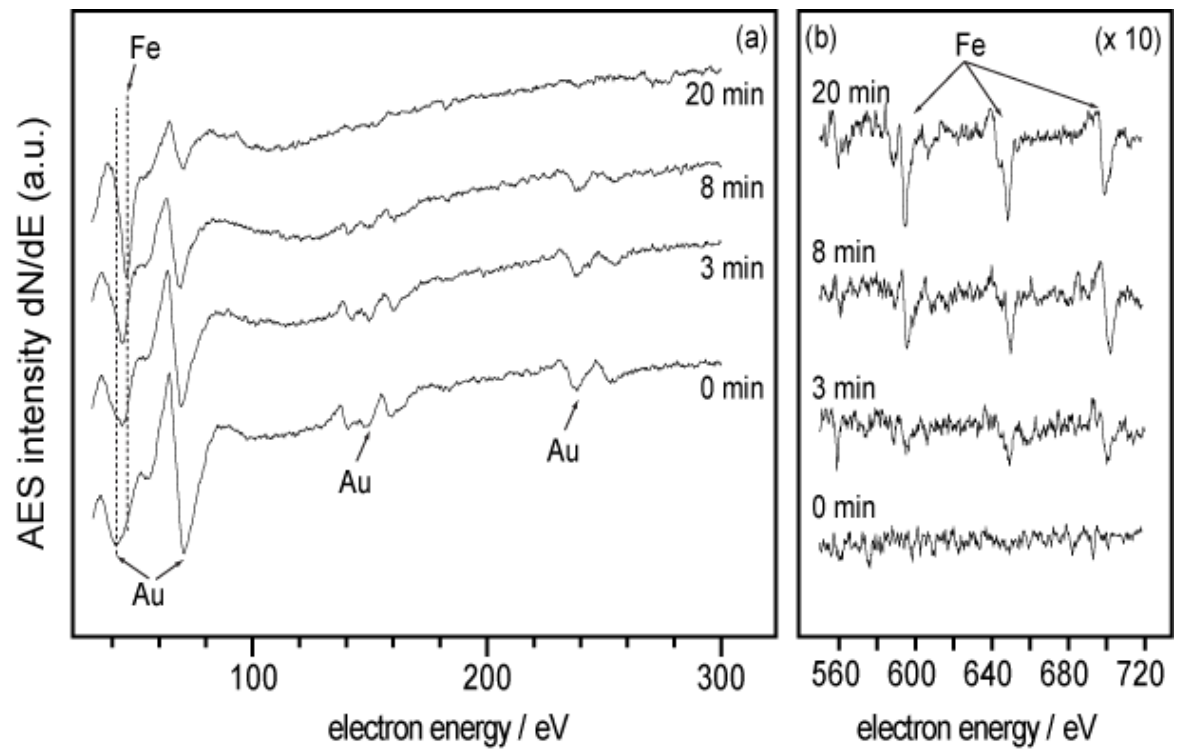

Figure 13. AES spectra in the (a) $40-300 \mathrm{eV}$, and (b) $550-720 \mathrm{eV}$ (x10) regions of an $\mathrm{Au}\{111\}$ surface with increasing exposure to Fe.

Deposition of Fe on the $\mathrm{Au}\{111\}$ surface caused the disappearance of the LEED satellite spots typical of the herringbone reconstruction (Fig. 14), indicating that this was at least partially affected as a result of the accumulation of Fe. The evolution of the LEED pattern observed under this treatment is consistent with previous studies on the epitaxial growth of $\mathrm{Fe}$ on $\mathrm{Au}\{111\}$. At low coverage iron is known to nucleate forming polygonal one atom thick islands whose spacing is determined by the underlying $\mathrm{Au}\{111\}$ herringbone reconstruction geometry $[\underline{44}, \underline{46}, \underline{47}]$. These islands grow laterally with increasing coverage disrupting the underlying $\mathrm{Au}\{111\}$ surface structure, and thus decreasing the sharpness of the diffracted beams in the LEED pattern, as observed in Fig. 14.
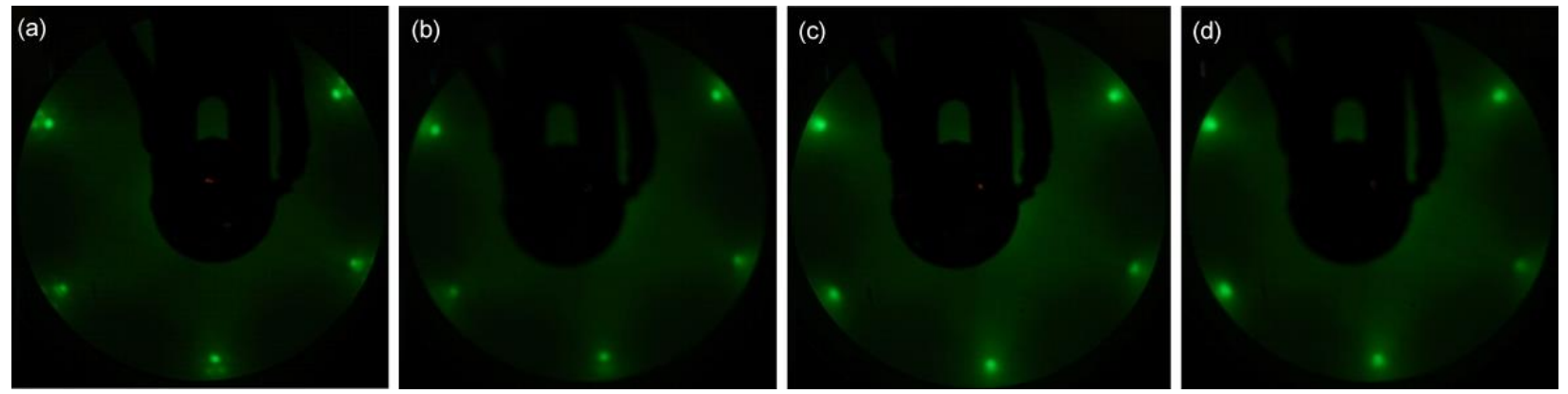
Figure 14. LEED data of (a) clean $\mathrm{Au}\{111\}$; and after Fe e-beam deposition for (b) 1 minute; (c) 5 minutes; and (d) 8 minutes, and subsequent anneal to $600 \mathrm{~K}$

Following Fe deposition on $\mathrm{Au}\{111\}$ we attempted the sulphurization of surface Fe by annealing this surface to $673 \mathrm{~K}$ in a $\mathrm{H}_{2} \mathrm{~S}$ atmosphere $\left(1 \times 10^{-6}\right.$ mbar). No S peaks were detected in AES, and no desorption features appeared in the $\mathrm{m} / \mathrm{z}=2, \mathrm{~m} / \mathrm{z}=32$ and $\mathrm{m} / \mathrm{z}=34\left(\mathrm{H}_{2}, \mathrm{~S}\right.$, and $\left.\mathrm{H}_{2} \mathrm{~S}\right)$ TPD spectra after exposure to $\mathrm{H}_{2} \mathrm{~S}$ at $300 \mathrm{~K}$, indicating that no $\mathrm{S}$ intake occurs on $\mathrm{Fe} / \mathrm{Au}\{111\}$ surfaces prepared under these conditions. LEED data also remained visually unchanged with respect to Fig. 14 (a-d).

We then investigated the electron-deposition of Fe under an atmosphere of $\mathrm{H}_{2} \mathrm{~S}\left(1 \times 10^{-6} \mathrm{mbar}\right)$ at $400 \mathrm{~K}$, followed by annealing to $673 \mathrm{~K}$ (under the same pressure of $\mathrm{H}_{2} \mathrm{~S}$ ) for 15 minutes. Fig. 15 shows the evolution of $\mathrm{S}(153 \mathrm{eV})$ AES peaks with increasing exposure times. A spectrum corresponding to the $\mathrm{Au}\{111\}$ surface after $60 \mathrm{~L}$ exposure to $\mathrm{H}_{2} \mathrm{~S}$ included in Fig. 14 indicates that no accumulation of sulphur occurs under these conditions without Fe deposition [45].This indicates that the parallel evolution of $\mathrm{Fe}$ and S AES peaks have a direct correlation, implying the formation of $\mathrm{Fe}_{\mathrm{x}} \mathrm{S}_{\mathrm{y}}$ on the $\mathrm{Au}\{111\}$ surface.

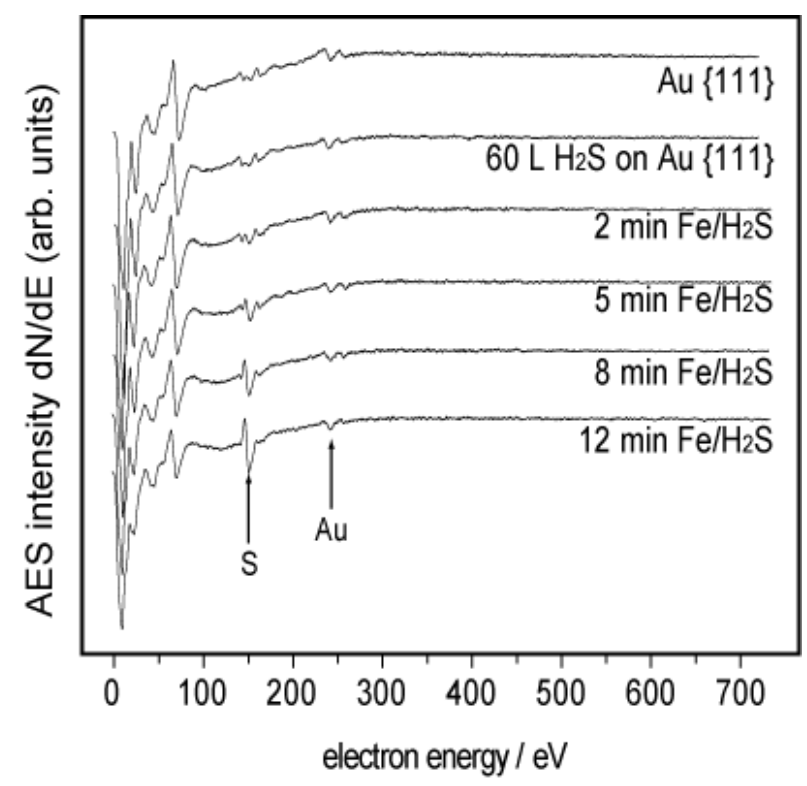

Figure 15. AES spectra in the $0-700 \mathrm{eV}$ region for a clean $\mathrm{Au}\{111\}$ crystal before and after $60 \mathrm{~L}$ exposure to $\mathrm{H}_{2} \mathrm{~S}$, and increasing e-beam deposition of Fe under a pressure of $10^{-6}$ mbar of $\mathrm{H}_{2} \mathrm{~S}$ at $400 \mathrm{~K}$. 
In contrast with the lack of change in the LEED patterns observed after exposure to $\mathrm{H}_{2} \mathrm{~S}$ of a Fe/Au\{111\} surface, the co-adsorption of $\mathrm{Fe}$ and $\mathrm{H}_{2} \mathrm{~S}$ did generate new patterns as observed in Fig. 16. The increasing coverage of $\mathrm{Fe}_{\mathrm{x}} \mathrm{S}_{\mathrm{y}}$ caused not only the dissipation of the herringbone-related spots, but the generation of completely new patterns, indicating that this method of co-deposition of $\mathrm{Fe}$ and $\mathrm{S}$ generates new ordered structures on the $\mathrm{Au}\{111\}$ surface. It is not within the scope of this article to discuss the structural details indicated by the LEED patterns, but it is clear that this new pattern is a consequence of the formation of $\mathrm{Fe}_{\mathrm{x}} \mathrm{S}_{\mathrm{y}}$ structures on the $\mathrm{Au}\{111\}$ surface. This is consistent with previous reports of the epitaxial growth of iron sulphide nanostructures nucleated on the kinks of the herringbone reconstruction on $\mathrm{Au}\{111\}$ [45].
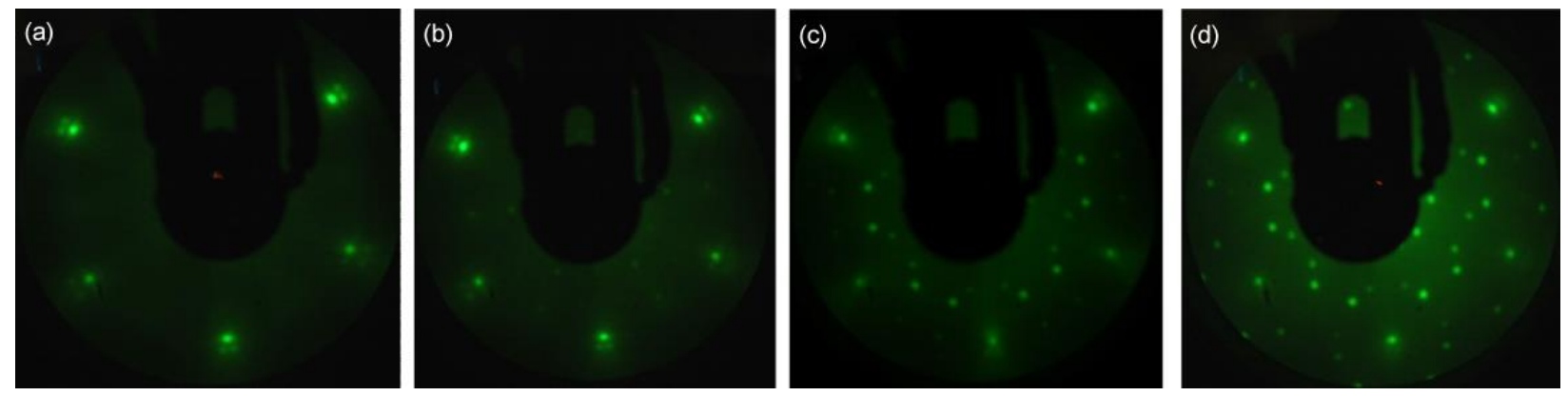

Figure 16. LEED patterns of (a) clean $\mathrm{Au}\{111\}$ surface before, and after e-beam deposition of Fe under a pressure of $10^{-6}$ mbar of $\mathrm{H}_{2} \mathrm{~S}$ at $400 \mathrm{~K}$ for (b) 2 minutes; (c) 5 minutes; and (d) 8 minutes.

\subsection{Background gas exposure to nitrogen}

The adsorption of $\mathrm{N}_{2}$ on the $\mathrm{Fe}_{\mathrm{x}} \mathrm{S}_{\mathrm{y}} / \mathrm{Au}\{111\}$ surface was then investigated using reflection absorption infrared spectroscopy (RAIRS) and TPD. Background exposure of different coverages of $\mathrm{Fe}_{\mathrm{x}} \mathrm{S}_{\mathrm{y}}$ on $\mathrm{Au}\{111\}$ (measured by $\mathrm{AES}$ and LEED) to $\mathrm{N}_{2}$ at pressures up to 1 bar at $300 \mathrm{~K}$ show no measurable IR bands or $\mathrm{N}_{2}$ desorption peaks. This suggest that, at least under the experimental conditions examined so far, $\mathrm{Fe}_{\mathrm{x}} \mathrm{S}_{\mathrm{y}}$ nanostructures on $\mathrm{Au}\{111\}$ do not promote the adsorption of $\mathrm{N}_{2}$ at room temperature. Nevertheless, we have not yet investigated the changes in adsorption characteristics of $\mathrm{N}_{2}$ on $\mathrm{Fe}_{\mathrm{x}} \mathrm{S}_{\mathrm{y}}$ nanostructures under similar conditions to those attempted for $\mathrm{FeS}_{2}\{100\}$ surfaces, to make a rigorous 
comparison between both materials. Such comparison would involve a much more intensive investigation of the growth characteristics of $\mathrm{Fe}_{\mathrm{x}} \mathrm{S}_{\mathrm{y}}$ nanostructures on $\mathrm{Au}\{111\}$ under a wide range of conditions. Ideally, one would augment these studies with additional characterisation techniques, including scanning tunnelling microscopy (STM) and X-Ray Photoemission Spectroscopy (XPS) in order to correlate morphological and compositional changes in the nanostructures to any possible changes in activity that might be observed.

\section{Conclusions}

In this work we have demonstrated an efficient and reproducible procedure to prepare a clean and wellordered $\mathrm{FeS}_{2}\{100\}$ surface. Ion bombardment preferentially removes $\mathrm{S}$ from the surface, causing structural and compositional changes that cannot be fully recovered by subsequent annealing. We have shown that an ex situ acid pre-treatment consisting in sequential ultrasonication in isopropanol, deionized water, and $1 \mathrm{M} \mathrm{HCl}$ solution can greatly improve the efficiency of the following in vacuo cleaning. Few cycles of $200 \mathrm{eV} \mathrm{He}$ sputtering followed by $600 \mathrm{~K}$ annealing are then needed to produce a clean $\mathrm{FeS}_{2}\{100\}$ surface compared to much longer cleaning procedures reported in the literature.

We have reported the interactions of nitrogen, hydrogen and ammonia with naturally-grown pristine $\mathrm{FeS}_{2}\{100\}$ surfaces. $\mathrm{N}_{2}$ adsorbs on $\mathrm{FeS}_{2}\{100\}$ surfaces molecularly at $105 \mathrm{~K}$ under UHV conditions, desorbing at $130 \mathrm{~K}$. Molecular $\mathrm{H}_{2}$ does not adsorb on this surface under similar conditions. Neither $\mathrm{N}_{2}$ nor $\mathrm{H}_{2}$ dissociatively chemisorb on $\mathrm{FeS}_{2}\{100\}$ at pressures up to 1 bar. Nevertheless, atomic surface $\mathrm{N}$ and $\mathrm{H}$ can be generated by exposing $\mathrm{FeS}_{2}\{100\}$ surfaces to excited nitrogen species, and hydrogen in the presence of a hot Ta filament, respectively. $\mathrm{N}_{\mathrm{ads}}$ recombinatively desorbs in two distinctive peaks at 405 $\mathrm{K}$ and $520 \mathrm{~K} . \mathrm{N}_{\mathrm{ads}}$ species desorbing at $405 \mathrm{~K}$ have been assigned as interstitially bonded in pristine (nondefective) sites, whereas species desorbing at $520 \mathrm{~K}$ are related to $\mathrm{S}$-depleted sites and therefore assigned as substitutional species. $\mathrm{H}_{\mathrm{ads}}$ recombinatively desorbs at $225 \mathrm{~K}$ and it also combines with lattice $\mathrm{S}$ generating $\mathrm{H}_{2} \mathrm{~S}$, which desorbs at $260 \mathrm{~K}$. The co-adsorption of $\mathrm{N}_{\mathrm{ads}}$ and $\mathrm{H}_{\mathrm{ads}}$ on $\mathrm{FeS}_{2}\{100\}$ readily forms $\mathrm{NH}_{3}$, which then desorb at $260 \mathrm{~K}$. The facile reaction between of $\mathrm{N}_{\mathrm{ads}}$ and $\mathrm{H}_{\mathrm{ads}}$ to form $\mathrm{NH}_{3}$ on $\mathrm{FeS}_{2}\{100\}$ 
is related to the relatively weak desorption energies of these species on iron sulphide.

Molybdenum was also deposited on the $\mathrm{FeS}_{2}\{100\}$ surface, but no evidence of $\mathrm{N}_{2}$ or $\mathrm{H}_{2}$ dissociative adsorption was subsequently observed. We note that $\mathrm{S}$ easily diffuses from the iron sulphide substrate to the newly formed Mo-rich layer, which could explain the inability of molybdenum to dissociative adsorb $\mathrm{N}_{2}$ and $\mathrm{H}_{2}$. Similarly to the case of the pristine $\mathrm{FeS}_{2}\{100\}$ surface, hydrogen adsorbs on the $\mathrm{MoS}_{\mathrm{x}} / \mathrm{FeS}_{2}\{100\}$ surface in the presence of a hot Ta filament, leading to desorption peaks of $\mathrm{H}_{2} \mathrm{~S}$ at 375 $\mathrm{K}$, and $\mathrm{H}_{2}$ at $350-400 \mathrm{~K}$. When annealing a Mo-rich layer to $600 \mathrm{~K}$, a well-ordered $\operatorname{MoS}_{2}\{0001\}$ overlayer is formed on $\mathrm{FeS}_{2}\{100\}$, but again no evidence of $\mathrm{N}_{2}$ or $\mathrm{H}_{2}$ dissociative adsorption was observed in this case.

We have also studied the interaction of $\mathrm{N}_{2}$ and $\mathrm{H}_{2}$ with $\mathrm{Fe}_{\mathrm{x}} \mathrm{S}_{\mathrm{y}}$ nanoclusters formed on $\mathrm{Au}\{111\}$. The produced nanoclusters promote the dissociative chemisorption of neither $\mathrm{N}_{2}$ nor $\mathrm{H}_{2}$ at pressures up to 1 bar. Although no clear evidence for a strong interaction between $\mathrm{N}_{2}$ and the $\mathrm{Fe}_{\mathrm{x}} \mathrm{S}_{\mathrm{y}}$ cluster is observed, we consider this a promising strategy to explore the activity of iron sulphur clusters of different sizes and compositions in the context of bioinspired routes for ammonia synthesis, for which this work may represent a valuable initial benchmark.

\section{Acknowledgements}

The authors warmly thank Dr S.M. Driver and Professor D.A. King for their contributions to our earlier publications on this topic. We also thank the EPSRC for financial support, and TL thanks the Cambridge Overseas Research Student Award Scheme and the Gates Cambridge Trust for funding.

\section{References}

[1] V. Smil, Nature, 400 (1999) 415-415. 
[2] I. Rafiqul, C. Weber, B. Lehmann, A. Voss, Energy, 30 (2005) 2487-2504.

[3] W. Zhou, B. Zhu, Q. Li, T. Ma, S. Hu, C. Griffy-Brown, Energy Policy, 38 (2010) 3701-3709.

[4] P.J. Crutzen, A.R. Mosier, K.A. Smith, W. Winiwarter, in: J.P. Crutzen, G.H. Brauch (Eds.) Paul J. Crutzen: A Pioneer on Atmospheric Chemistry and Climate Change in the Anthropocene, Springer International Publishing, Cham, 2016, pp. 227-238.

[5] J.W. Erisman, M.A. Sutton, J. Galloway, Z. Klimont, W. Winiwarter, Nature Geosci, 1 (2008) 636-639.

[6] T. Travis, Chemistry and Industry, (1993) 581-585.

[7] S. Matassa, D.J. Batstone, T. Hülsen, J. Schnoor, W. Verstraete, Environmental Science \& Technology, 49 (2015) 5247-5254.

[8] B.M. Hoffman, D. Lukoyanov, Z.-Y. Yang, D.R. Dean, L.C. Seefeldt, Chemical Reviews, 114 (2014) 40414062.

[9] X. Zhang, D.L. McRose, R. Darnajoux, J.P. Bellenger, F.M.M. Morel, A.M.L. Kraepiel, Biogeochemistry, 127 (2016) 189-198.

[10] J.B. Howard, D.C. Rees, Chemical Reviews, 96 (1996) 2965-2982.

[11] B.M. Hoffman, D. Lukoyanov, D.R. Dean, L.C. Seefeldt, Accounts of Chemical Research, 46 (2013) 587-595.

[12] T. Spatzal, J. Schlesier, E.-M. Burger, D. Sippel, L. Zhang, S.L.A. Andrade, D.C. Rees, O. Einsle, Nat Commun, 7 (2016).

[13] O. Einsle, F.A. Tezcan, S.L.A. Andrade, B. Schmid, M. Yoshida, J.B. Howard, D.C. Rees, Science, 297 (2002) 1696-1700.

[14] G. Ertl, Catalysis Reviews, 21 (1980) 201-223.

[15] T. Liu, I. Temprano, S.J. Jenkins, D.A. King, The Journal of Chemical Physics, 139 (2013) 184708.

[16] P. Iyngaran, D.C. Madden, D.A. King, S.J. Jenkins, The Journal of Physical Chemistry C, 118 (2014) 1218412194.

[17] P. Iyngaran, D.C. Madden, S.J. Jenkins, D.A. King, Proceedings of the National Academy of Sciences, 108 (2011) 925-930.

[18] S.C. Lee, R.H. Holm, Chemical Reviews, 104 (2003) 1135-1158.

[19] D. Rickard, G.W. Luther, Chemical Reviews, 107 (2007) 514-562.

[20] G.D. Cody, N.Z. Boctor, J.A. Brandes, T.R. Filley, R.M. Hazen, H.S. Yoder Jr, Geochimica et Cosmochimica 
Acta, 68 (2004) 2185-2196.

[21] R. Murphy, D.R. Strongin, Surface Science Reports, 64 (2009) 1-45.

[22] M.A.A. Schoonen, Y. Xu, Astrobiology, 1 (2001) 133-142.

[23] G. Wächtershäuser, Science, 289 (2000) 1307-1308.

[24] T. Liu, I. Temprano, S.J. Jenkins, D.A. King, S.M. Driver, Physical Chemistry Chemical Physics, 14 (2012) 11491-11499.

[25] T. Liu, I. Temprano, S.J. Jenkins, D.A. King, S.M. Driver, The Journal of Physical Chemistry C, 117 (2013) 10990-10998.

[26] M. Guevremont Jeffrey, R. Strongin Daniel, A.A. Schoonen Martin, American Mineralogist, 1998 , pp. 1246.

[27] J.M. Guevremont, J. Bebie, A.R. Elsetinow, D.R. Strongin, M.A.A. Schoonen, Environmental Science \& Technology, 32 (1998) 3743-3748.

[28] J.M. Guevremont, D.R. Strongin, M.A.A. Schoonen, Surface Science, 391 (1997) 109-124.

[29] C.M. Eggleston, J.-J. Ehrhardt, W. Stumm, American Mineralogist, 81 (1996) 1036-1056.

[30] K.M. Rosso, U. Becker, M.F. Hochella, American Mineralogist, 84 (1999) 1535-1548.

[31] K.M. Rosso, U. Becker, M.F.J. Hochella, American Mineralogist, 84 (1999) 1549-1561.

[32] S. Chaturvedi, R. Katz, J. Guevremont, M.A.A. Schoonen, D.R. Strongin, American Mineralogist, 81 (1996) 261-264.

[33] N. Moslemzadeh, M. Tamara, R. Raval, D. Prior, M.R. Preston, Surface and Interface Analysis, 41 (2009) 1-5.

[34] Y.C. Lee, P.A. Montano, Surface Science, 143 (1984) 442-468.

[35] A.N. Buckley, R. Woods, Applied Surface Science, 27 (1987) 437-452.

[36] M.-C. Tsai, U. Ship, I.C. Bassignana, J. Küppers, G. Ertl, Surface Science, 155 (1985) 387-399.

[37] T. Liu, I. Temprano, D.A. King, S.M. Driver, S.J. Jenkins, Chemical Communications, 51 (2015) $537-540$.

[38] D.A. King, F.C. Tompkins, Transactions of the Faraday Society, 64 (1968) 496-506.

[39] R. Bafrali, A.T. Bell, Surface Science, 278 (1992) 353-363.

[40] M. Salmeron, G.A. Somorjai, Chemical Physics Letters, 90 (1982) 105-107.

[41] M.H. Farias, A.J. Gellman, G.A. Somorjai, Surface Science, 140 (1984) 181-196.

[42] B.K. Min, A.R. Alemozafar, M.M. Biener, J. Biener, C.M. Friend, Topics in Catalysis, 36 77-90.

[43] S.M. Driver, T. Zhang, D.A. King, Angewandte Chemie International Edition, 46 (2007) 700-703. 
[44] A. Delga, J. Lagoute, V. Repain, C. Chacon, Y. Girard, M. Marathe, S. Narasimhan, S. Rousset, Physical Review B, 84 (2011) 035416.

[45] J. Kibsgaard, A. Tuxen, K.G. Knudsen, M. Brorson, H. Tops $\tilde{A}_{s}$ e, E. LÃ'gsgaard, J.V. Lauritsen, F. Besenbacher, Journal of Catalysis, 272 (2010) 195-203.

[46] N.A. Khan, C. Matranga, Surface Science, 602 (2008) 932-942.

[47] B. Voigtlander, G. Meyer, N.M. Amer, Surface Science, 255 (1991) L529-L535.

1. Bozso, F., et al., Interaction of nitrogen with iron surfaces: I. Fe(100) and Fe(111). Journal of Catalysis, 1977. 49(1): p. 18-41.

2. Ertl, G., M. Weiss, and S.B. Lee, The role of potassium in the catalytic synthesis of ammonia. Chemical Physics Letters, 1979. 60(3): p. 391-394.

3. Lee, S.B., M. Weiss, and G. Ertl, Adsorption of potassium on iron. Surface Science, 1981. 108(2): p. 357367.

4. $\quad$ Ertl, G., S.B. Lee, and M. Weiss, Adsorption of nitrogen on potassium promoted Fe(111) and (100) surfaces. Surface Science, 1982. 114(2): p. 527-545.

5. Rettner, C.T. and H. Stein, Effect of Translational Energy on the Chemisorption of $\$\{\mid$ mathrm $\{N\}\}\{2\} \$$ on Fe(111): Activated Dissociation via a Precursor State. Physical Review Letters, 1987. 59(24): p. $2768-2771$.

6. Strongin, D.R. and G.A. Somorjai, The effects of potassium on ammonia synthesis over iron single-crystal surfaces. Journal of Catalysis, 1988. 109(1): p. 51-60. 